\title{
Roles of Major RNA Adenosine Modifications in Head and Neck Squamous Cell Carcinoma
}

\begin{abstract}
Xing-xing Huo ${ }^{1,2 t}$, Shu-jie Wang ${ }^{2 \dagger}$, Hang Song ${ }^{3 \dagger}$, Ming-de $\mathrm{Li}^{1}$, Hua $\mathrm{Yu}^{4}$, Meng Wang ${ }^{2}$, Hong-xiao Gong ${ }^{1}$, Xiao-ting Qiu ${ }^{1}$, Yong-fu Zhu ${ }^{1 *}$ and Jian-ye Zhang ${ }^{5 *}$

${ }^{1}$ Experimental Center of Clinical Research, Scientific Research Department, The First Affiliated Hospital of Anhui University of Chinese Medicine, Hefei, China, ${ }^{2}$ Anhui Province Key Laboratory of Medical Physics and Technology, Institute of Health and Medical Technology, Hefei Institutes of Physical Science, Chinese Academy of Sciences, Hefei, China, ${ }^{3}$ Department of Biochemistry and Molecular Biology, School of Integrated Chinese and Western Medicine, Anhui University of Chinese Medicine, Hefei, China, ${ }^{4}$ Institute of Chinese Medical Sciences, State Key Laboratory of Quality Research in Chinese Medicine, University of Macau, Macao, China, ${ }^{5}$ Key Laboratory of Molecular Target and Clinical Pharmacology and the State Key Laboratory of Respiratory Disease, School of Pharmaceutical Sciences and the Fifth Affiliated Hospital, Guangzhou Medical University, Guangzhou, China
\end{abstract}

OPEN ACCESS

Edited by:

Yingjie Zhang,

Shandong University, China

Reviewed by:

Yan Liu,

Nanjing Normal University, China

Cristina Barbagallo,

University of Catania, Italy

${ }^{*}$ Correspondence:

Yong-fu Zhu

zyf240@ahtcm.edu.cn

Jian-ye Zhang

jianyez@163.com

${ }^{\dagger}$ These authors have contributed equally to this work.

Specialty section:

This article was submitted to Experimental Pharmacology and Drug

Discovery,

a section of the journal

Frontiers in Pharmacology

Received: 19 September 2021 Accepted: 09 November 2021

Published: 25 November 2021

Citation:

Huo X-x, Wang S-j, Song H, Li M-d,

Yu $H$, Wang $M$, Gong $H-x$, Qiu X-t,

Zhu Y-f and Zhang J-y (2021) Roles of

Major RNA Adenosine Modifications in

Head and Neck Squamous

Cell Carcinoma.

Front. Pharmacol. 12:779779.

doi: 10.3389/fphar.2021.779779
Head and neck squamous cell carcinoma (HNSCC) is the sixth most common cancer malignancy worldwide and is known to have poor prognosis. The pathogenesis behind the development of HNSCC is not fully understood. Modifications on RNA are involved in many pathophysiological processes, such as tumor development and inflammation. Adenosinerelated RNA modifications have shown to be linked to cancer and may play a role in cancer occurrence and development. To date, there are at least 170 different chemical RNA modifications that modify coding and non-coding RNAs (ncRNAs). These modifications affect RNA stability and transcription efficiency. In this review, we focus on the current understanding of the four major RNA adenosine modifications ( $\mathrm{N}^{6}$-Methyladenosine, $\mathrm{N}^{1}$ Methyladenosine, Alternative Polyadenylation Modification and A-to-I RNA editing) and their potential molecular mechanisms related to HNSCC development and progression. We also touch on how these RNA modifications affect treatment of HNSCCs.

Keywords: RNA modification, N 6-methyladenosine, N 1-methyladenosine, alternative polyadenylation, adenosineto-inosine editing, head and neck squamous cell carcinoma, immunotherapy

\section{INTRODUCTION}

Head and neck squamous cell carcinoma (HNSCCs) mainly occurs in the mucosal epithelium of the oral cavity, pharynx or larynx. It is the sixth most common cancer worldwide, with over 800,000 cases diagnosed annually and an increasing incidence (Ferlay et al., 2019; Sung et al., 2021). Exposure to tobacco-derived carcinogens, excessive alcohol consumption, human papillomavirus and EBV are some of the triggers associated with HNSCC (Johnson et al., 2020). The molecular mechanisms behind HNSCC pathogenesis and development have not been fully elucidated. In recent years, advances in molecular biology expanded the understanding of epigenetics, especially posttranscriptional modifications of RNA, which play important roles in cell fate determination, proliferation, metabolism and many pathological processes.

New messenger RNA (mRNA) transcripts require additional processing and modifications before translation and protein synthesis. RNA modifications regulate most steps of gene expression, from indirectly controlling DNA transcription through transcription factors, to 


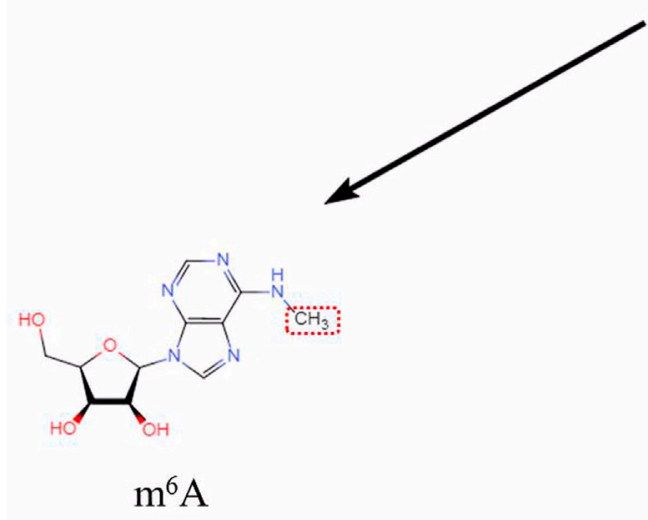

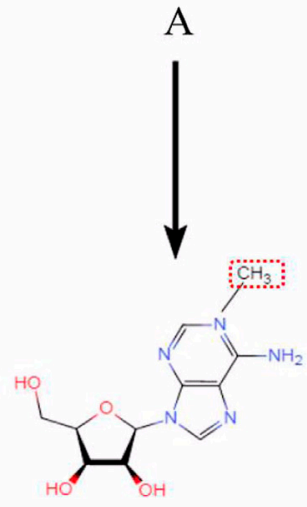

$\mathrm{m}^{1} \mathrm{~A}$
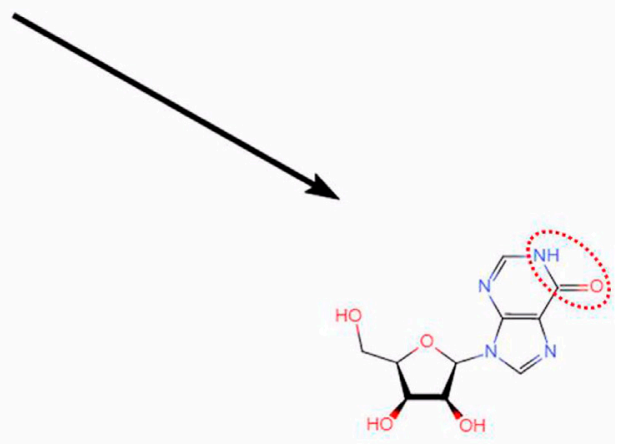

I

FIGURE 1 | Three adenine-associated RNA modifications $\left(N^{6}\right.$-methyladenosine $\left(m^{6} A\right), N^{1}$-methyladenosine ( $\left.m^{1} A\right)$ and Adenosine to Inosine $(A$ to $\left.I)\right)$. Chemical structures of three adenine-associated RNA modifications are shown.

directly affecting mRNA translation (Delaunay and Frye, 2019). Many RNA modifications have been uncovered thanks to next generation sequencing technologies. Some RNA modifications are difficult to study since there may be an inability to distinguish between certain nucleotides ( $\mathrm{Li}$ et al., 2019c). To date, there are at least 170 different chemical RNA modifications known to modify coding and non-coding RNAs (ncRNAs) (Ramanathan et al., 2016; Xu et al., 2017; Dimitrova et al., 2019). The heavy nucleotide adenine is the most commonly modified in RNA. In this review, we focus on adenine-associated RNA modifications, including $\mathrm{m}^{6} \mathrm{~A}$ methylation, $\mathrm{m}^{1} \mathrm{~A}$ methylation, A-to-I RNA editing (Figure 1) and APA (Figure 2). We also discuss adenine-associated RNA modifications in regulating gene expression in HNSCC.

\section{ADENINE-RELATED RNA MODIFICATIONS}

\section{$\mathbf{N}^{6}$-Methyladenosine Modifications}

$\mathrm{m}^{6} \mathrm{~A}$ is the most abundant and well-defined internal modification in mRNA. Methylation of the sixth nitrogen atom of RNA base A affects RNA stability and translation efficiency (Figure 3). This modification is programmed by $\mathrm{m}^{6} \mathrm{~A}$-methyltransferases, including methyltransferase-like 3 (METTL3), methyltransferase-like 14 (METTL14), WTAP, RNA-binding motif protein 15 (RBM15), RNA-binding motif protein 15B (RBM15B), ZC3H13 and KIAA1429.

\section{N6-Methyladenosine Writers}

The $\mathrm{m}^{6} \mathrm{~A}$ modification process undergoes first-order catalysis involving the two methyltransferase complexes (writers)
METTL14 and METTL3. METTL3 coverts adenosine to $\mathrm{m}^{6} \mathrm{~A}$ through its methyltransferase domain, and METTL14 is responsible for the recognition of RNA substrates. ZC3H13, RBM15 and VIRMA are also incorporated into the methyltransferase complex to regulate METTL14 and METTL3 functions.

\section{N6-Methyladenosine Erasers}

The deposition of $\mathrm{N}^{6}$-methyladenosine on RNA is reversible through coordination of methyltransferases and demethylases. Fat mass and obesity-associated protein (FTO) and AlkB homolog 5 (ALKBH5) have been identified as members of non-heme $\mathrm{Fe}$ (II)/a -ketoglutarate-dependent dioxygenases. AlkB homolog 3 (ALKBH3), another member of the family, preferentially acts on $\mathrm{m}^{6} \mathrm{~A}$ in tRNAs. The mechanisms where $\mathrm{m}^{6} \mathrm{~A}$ methylation selectively and dynamically targets specific regions of the transcriptome are not fully understood. It is anticipated that additional $\mathrm{m}^{6} \mathrm{~A}$ demethylases will be discovered.

\section{N6-Methyladenosine Readers}

$\mathrm{m}^{6} \mathrm{~A}$ modifications are unique recognition elements that bind proteins to readers and drive biochemical processes that occur in labeled RNA. The RNA-binding domain or the YTH domain contains YTH-domain proteins 1 and 2 family members (YTHDF1, YTHDF2, YTHDF3, YTHDC1 and YTHDC2). More recently, other readers have been identified, including insulin-like growth factor 2 mRNA-binding proteins (IGF2BP1, IGF2BP2, and IGF2BP3) and heterogeneous ribonucleic proteins (HNRNPC and HNRNPA2/B1). These proteins are highly expressed in different cancers and are involved in various molecular mechanisms. These proteins are not always dependent on the recognition of $\mathrm{m}^{6} \mathrm{~A}$. 
A CR-APA
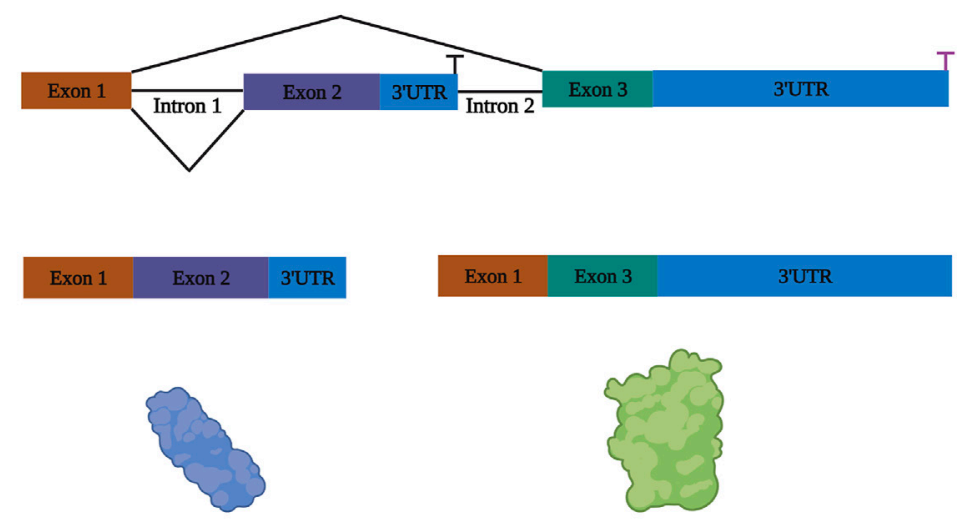

B UTR-APA
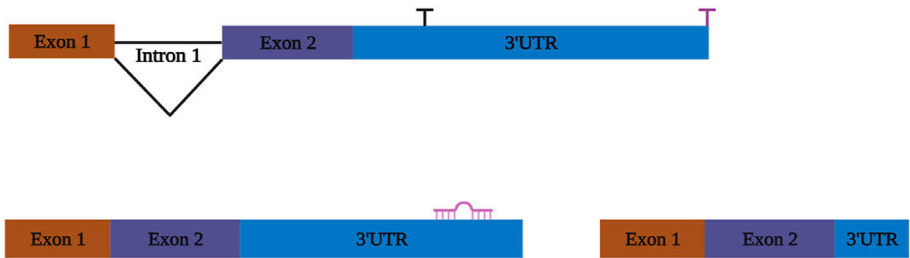

Identical protein
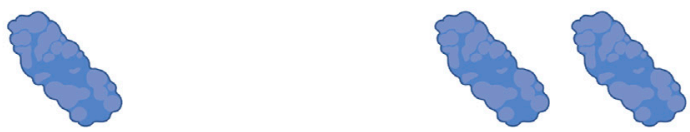

FIGURE 2 | The mechanism of alternative polyadenylation (APA). (A) One form of APA, termed coding region alternative polyadenylation (CR-APA), occurs when the alternative polyA sites (PASs) are located within exons or introns. (B) Another form of APA is known as untranslated region alternative polyadenylation (UTR-APA) when alternative PASs are located in different regions of the $3^{\prime}-U T R$, resulting in the identical protein isoforms.

\section{$\mathbf{N}^{\mathbf{1}}$-Methyladenosine Modifications}

$\mathrm{m}^{1} \mathrm{~A}$ is a reversible modification produced when a methyl group attaches to the $\mathrm{N}^{1}$ position of adenosine. TRMT61A, TRMT61B, TRMT10C and TRMT6 have the ability to generate $\mathrm{m}^{1} \mathrm{~A}$ modifications. It carries a positive charge when in physiological conditions and blocks the Watson-Crick interface, alters the structure of RNA, regulates protein-RNA interactions and affects the tertiary structure of ribosomes and translation (Shi et al., 2019). In mammals, the abundance of $\mathrm{m}^{1} \mathrm{~A}$ in tRNAs and rRNAs is significantly greater than the abundance of mRNAs. Most $\mathrm{m}^{1} \mathrm{~A}$ sites are located in the $5^{\prime}$-untranslated region $\left(5^{\prime}\right.$-UTR) of RNA (Dominissini et al., 2016). This modification affects both the occurrence and development of tumors by regulating gene expression and related biological processes.

\section{$\mathbf{N}^{\mathbf{1}}$-Methyladenosine Writers}

$\mathrm{m}^{1} \mathrm{~A}$ "writers" contain a methyltransferase complex, including TRMT6, TRMT61A, TRMT10C and TRMT61B (Safra et al., 2017; Dai et al., 2018). In eukaryotes, $\mathrm{m}^{1} \mathrm{~A}$ methyltransferases consist of TRMT6 and TRMT61A responsible for $\mathrm{m}^{1} \mathrm{~A} 58$ modifications of cytoplasmic tRNAs (Ozanick et al., 2005). TRMT6 plays a key role in tRNA binding (Anderson et al., 2000). Studies have shown that TRMT10C and TRMT61B catalytic sites are located at positions 9 and 58 of human mttRNAs, respectively (Chujo and Suzuki, 2012; Vilardo et al., 2012). These positions on mt-tRNAs also coincide with the presence of $\mathrm{m}^{1} \mathrm{~A}$ modifications (Ozanick et al., 2005). In addition, the tRNA $\mathrm{m}^{1} \mathrm{~A}$ enzyme also modifies $\mathrm{m}^{1} \mathrm{~A}$ modifications in mRNAs. For example, TRMT6/61A programs $\mathrm{m}^{1} \mathrm{~A}$ sites in some nuclear mRNAs with GUUCRA tRNA-like motifs, while TRMT61B methylates half of the known $\mathrm{m}^{1} \mathrm{~A}$ sites in mt-mRNAs (Li et al., 2017). Safra et al. also revealed that position 1374 of the mt-mRNA ND5 can be programmed into $\mathrm{m}^{1} \mathrm{~A}$ by TRMT10C (Safra et al., 2017). Additional $\mathrm{m}^{1} \mathrm{~A}$ mRNA enzymes may be discovered in the future.

\section{$\mathbf{N}^{\mathbf{1}}$-Methyladenosine Erasers}

$\mathrm{m}^{1} \mathrm{~A}$ "erasers," such as $\mathrm{m}^{1} \mathrm{~A}$ demethylase, remove methyl groups from $\mathrm{m}^{1} \mathrm{~A}$. ALKBH1 and ALKBH3 both exert $\mathrm{m}^{1} \mathrm{~A}$ demethylase activity and act as "erasers". Li et al. proposed that ALKBH1 and ALKBH3, both members of the ALKB family, participate in 


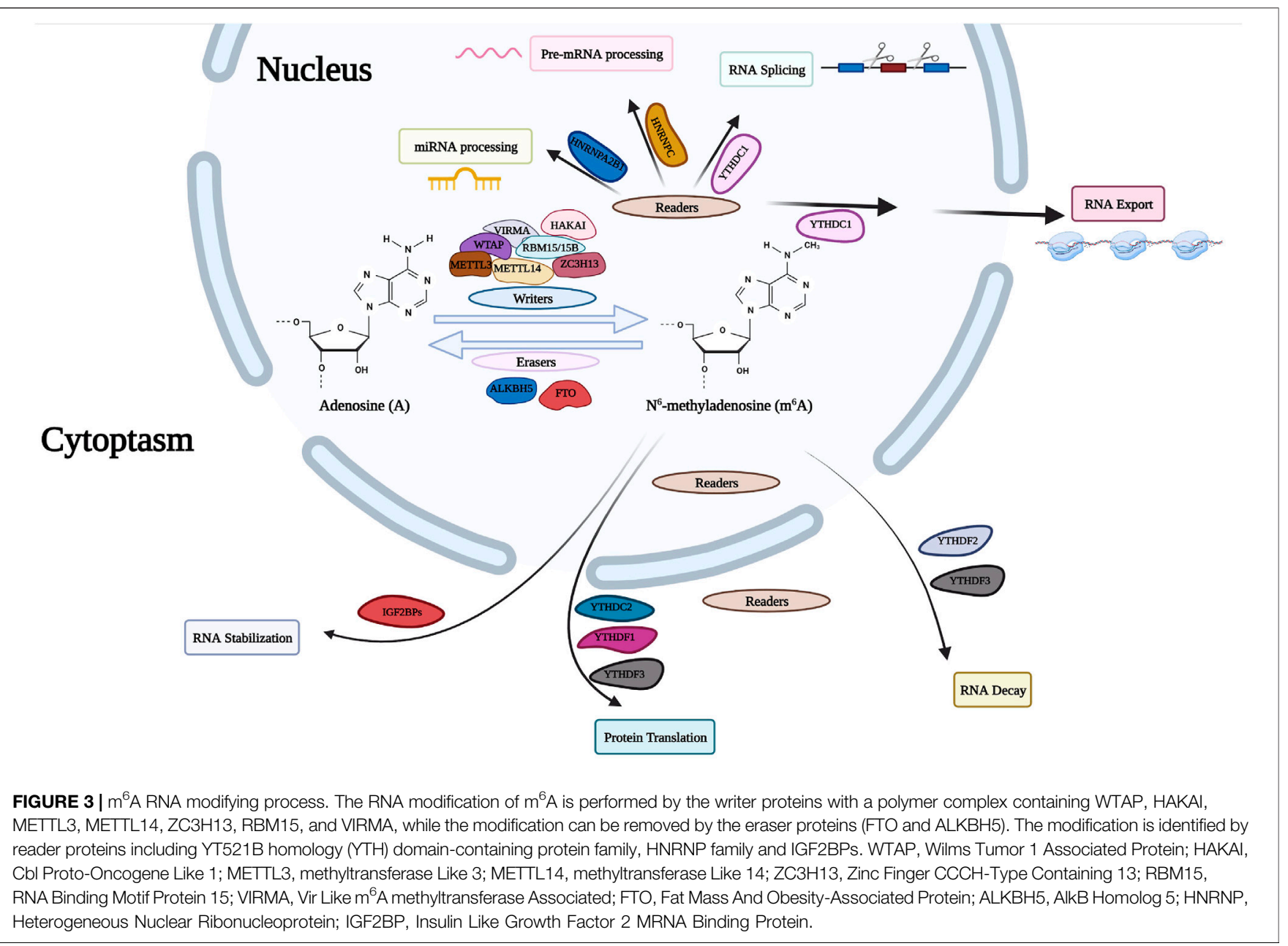

demethylation of $\mathrm{m}^{1} \mathrm{~A}$ sites in RNA (Li et al., 2016). Knocking out ALKBH1 increases $\mathrm{m}^{1} \mathrm{~A}$ methylation (Liu et al., 2016). Knockout of ALKBH3 increases $\mathrm{m}^{1} \mathrm{~A}$ levels in tRNAs and reduces protein synthesis in cancer cells (Ueda et al., 2017).

\section{$\mathbf{N}^{\mathbf{1}}$-Methyladenosine Readers}

The known "readers" for $\mathrm{m}^{1} \mathrm{~A}$ methylation include YTHDF1, YTHDF2, YTHDF3 and YTHDC1, which decode $\mathrm{m}^{1} \mathrm{~A}$ methylation markers and regulate $\mathrm{m}^{1} \mathrm{~A}$-related functions by mediating post-transcriptional regulation (Dai et al., 2018). A recent study revealed YTHDF1-3 and YTHDC1 as $\mathrm{m}^{1} \mathrm{~A}$ readers, but not YTHDC2 (Dai et al., 2018). Electrophoretic mobility studies indicated that the YTH domain of YTHDF1-3 and YTHDC1 binds to RNA with $\mathrm{m}^{1} \mathrm{~A}$ modifications. In contrast, the YTH domain of YTHDC2 does not appear to bind to RNA with $\mathrm{m}^{1} \mathrm{~A}$ modification. Proteins containing an $\mathrm{YTH}$ domain recognize $\mathrm{m}^{1} \mathrm{~A}$ modifications, proving that YTHDF1-3 and YTHDC1 may be readers of $\mathrm{m}^{1} \mathrm{~A}$ modifications. However, there is limited research on $\mathrm{m}^{1} \mathrm{~A}$ "readers", and more $\mathrm{m}^{1} \mathrm{~A}$ "readers" are expected to be uncovered in the future.

\section{Alternative Polyadenylation Modifications}

Transcripts containing $3^{\prime}$-untranslation (3'-UTR) or coding regions of different lengths are generated through alternative polyadenylation (APA) when poly (A) tails are added or removed to different sites on RNA (Sandberg et al., 2008; Tian and Manley, 2017; Ikeda et al., 2020) (Figures 2A,B). Different transcripts have variable $3^{\prime}$-UTR lengths as a result of polyA sites, which contributes to polymorphisms (Pan et al., 2008; Wang et al., 2008; Xia et al., 2014). During embryonic development, APA is present at large amounts on mRNA. The most common form present in differentiated cells is the long $3^{\prime}$-UTR version (Grassi et al., 2018).

APA can affect the transcription in multiple ways (Lin et al., 2012). First, APA changes the position of protein products, adjusting metabolism (Berkovits and Mayr, 2015). Second, some APAs are tissue-specific and quickly respond to signals to regulate gene expression (Passacantilli et al., 2017). Furthermore, APA plays an important role in posttranscriptional splicing and can produce abnormal protein isoforms (Meyer et al., 2017; Ma et al., 2018; Zhu et al., 2018). In addition, upstream mechanisms, such as RNA processing factors and binding proteins, regulate APA and ultimately downstream biological processes (Zheng and Tian, 2014).

The proximal poly (A) site is used to form mRNAs with short 3 UTRs in highly proliferating cells (Ji and Tian, 2009). Studies 
have shown that NUDT21 plays an important role in bladder cancer. NUDT21 regulates the expression of ANXA2 and LIMK2 through Wnt/beta-catenin and NF-kappaB signaling pathways. ANXA2 and LIMK2 act by APA (Wang et al., 2019a). Among the various risk factors related to the occurrence and development of cancer, APA is an important endogenous factor directly triggering malignant phenotypes. Specific APA events are closely related to the occurrence of malignant tumors and autoimmune diseases (Rajasekar et al., 2020). For example, high levels APA in cancer cells are often accompanied by loss of $3^{\prime}$-UTR inhibitory elements, indicating that APA plays a universal role in oncogene activation (Gruber and Zavolan, 2019). By studying the regulatory factors or mediators during the APA process, new diagnostic criteria or therapeutic targets for cancer and other diseases may be identified.

\section{Adenosine-to-Inosine Editing}

Epigenetic and post transcriptional mechanisms play important roles in gene expression and normal physiology editing is a posttranscriptional mechanism that changes the sequence of transcriptional RNA through post transcriptional modifications (Simpson and Emeson, 1996).

The most common form of RNA editing in higher eukaryotes includes A-to-I RNA editing, which occurs in double stranded RNA (dsRNA) where adenosine (A) forms inosine (I) through hydrolytic deamination (Roth et al., 2019). A-to-I editing alters amino acid sequences and affects other transcriptional processes, thereby promoting tumorigenesis and tumor progression through site-specific modifications of tumor-associated genes (Chen et al., 2017b; Hong et al., 2018; Xu et al., 2019a; Han et al., 2020). Adenosine deaminase (ADARs), including ADAR1, ADAR2 and ADAR3, catalyze this reaction (Valente and Nishikura, 2005; Yao et al., 2019). The ADAR family all contain a highly conserved C-terminal catalytic deaminase domain and several N-terminal dsRNA binding domains (Zinshteyn and Nishikura, 2009). The mammalian ADAR family consists of three structurally conserved members, ADAR1, ADAR2 and ADAR3 (Bass, 2002). ADAR1 and ADAR2 are expressed in most tissues and their catalytic activity has been observed for a while (Lehmann and Bass, 2000; Wong et al., 2001). ADAR3 is highly expressed in the central nervous system (Chen et al., 2000; Wang et al., 2019b). The ADAR1 protein has both a long (P150) and short (P110) isoform. ADAR1p110 is predominantly found in the nucleus, whereas ADAR1p150 is found in both the nucleus and cytoplasm. ADAR1p150 expression is driven by an interferon inducible promoter and is upregulated in situations of cellular stress or viral infection (Patterson and Samuel, 1995). ADAR1 plays an important role in A-to-I RNA editing and influences cancer development (Qin et al., 2014; Heraud-Farlow et al., 2019; Vlachogiannis et al., 2021). ADAR2 is present in the nucleus of cells and ADAR2 along with ADAR1 may both influence the function of neurons (Behm et al., 2017; Hosaka et al., 2019). ADAR3 exists as a monomer in vitro and is specifically expressed only in brain tissue, which may explain why it is thought to be catalytically inactive (Chen et al., 2000; Nishikura, 2010).

\section{ADENINE-RELATED RNA MODIFICATION REGULATION IN HEAD AND NECK SQUAMOUS CELL CARCINOMA The Role of $\mathbf{N}^{6}$-Methyladenosine in Head and Neck Squamous Cell Carcinoma}

Presently, it is generally believed that $m^{6} \mathrm{~A}$ methylation modifications play key roles in the occurrence and development of carcinomas. Most studies indicate that an increase of $\mathrm{m}^{6} \mathrm{~A}$ methylation levels promotes tumor growth, development and treatment resistance (Figure 4). Here, we review recent articles studying $\mathrm{m}^{6} \mathrm{~A}$ modifications in head and neck carcinoma. A summary of these compiled studies are presented in Table 1.

\section{N6-Methyladenosine Writers in Head and Neck Squamous Cell Carcinoma}

METTL3 is a common writer for $\mathrm{m}^{6} \mathrm{~A}$ methylation. It is highly expressed in gastric, bladder, colorectal and pancreatic cancers as well as, glioblastoma and other tumors. High levels of METTL3 indicate a poor prognosis for gastric cancer ( $\mathrm{Li}$ et al., 2019a; Li et al., 2019b; Han et al., 2019; Xia et al., 2019; Yue et al., 2019; Zhao and Cui, 2019; Wang et al., 2020a). METTL3 also plays an important role in head and neck carcinoma. A study by $\mathrm{Wu}$ et al. found that METTL3 regulates the $\mathrm{m}^{6} \mathrm{~A}$ methylation levels of circCUX1 and increases its stability in hypopharyngeal squamous cell carcinoma patients resistant to radiotherapy. The circCUX1 further inhibits caspase1 expression, reduces the release of inflammatory factors and increases the tolerability of tumor cells to radiotherapy. Knockout of circCUX1 increases the sensitivity of hypopharyngeal cancer cells to radiotherapy (Wu et al., 2021). Similarly, Ai et al. confirmed that METTL3 is highly expressed in oral squamous cell carcinoma (OSCC). METTL3 writes $\mathrm{m}^{6} \mathrm{~A}$ modifications in PRMT5 and PD-L1 and promotes the progression of OSCC by increasing $\mathrm{m}^{6} \mathrm{~A}$ editing (Ai et al., 2021). Interestingly, Liu et al. also found that the expression of METTL3 in two OSCC cohorts was significantly higher than in normal adjacent tissues, which was associated with a poor prognosis. METTL3 promotes proliferation, migration and invasion of OSCC cells in vitro by mediating $\mathrm{m}^{6} \mathrm{~A}$ modifications in the $3^{\prime}$-UTR of BMI1 mRNAs. METTL3 also cooperates with IGF2BP1 to promote the translation of BMI1 in OSCC. The METTL3- ${ }^{6} \mathrm{~A}-\mathrm{BMI} 1$ axis may serve as a therapeutic target or prognostic biomarker for OSCC (Liu et al., 2020). Meng et al. found that METTL3 was highly expressed in nasopharyngeal carcinoma (NPC) tissues, with increasing levels of expression associated with tumor stage. METTL3 is associated with the vitality and migration ability of NPC cells. In terms of mechanism, METTL3 binds and mediates $\mathrm{m}^{6} \mathrm{~A}$ modifications on EZH2 mRNAs, inhibiting EZH2 expression and upregulating CDKN1C expression. This increases the malignancy and promotes the development of NPC (Meng et al., 2020). We speculate that the METTL3-EZH2-CDKN1C regulatory axis may be closely related to $\mathrm{NPC}$, and $\mathrm{m}^{6} \mathrm{~A}$ methylation modifications affect its activation. 


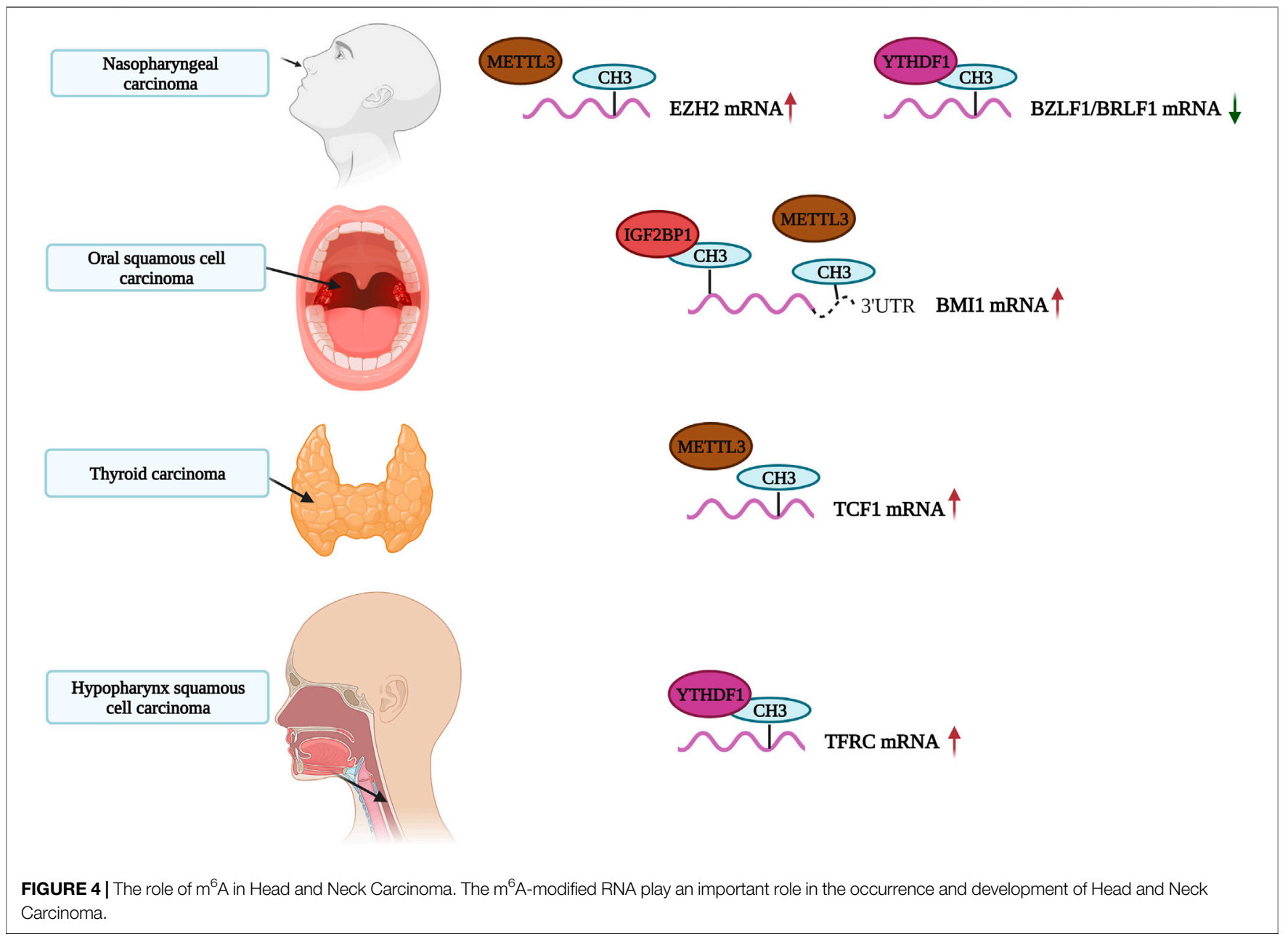

METTL3 and METTL14 also mediate $\mathrm{m}^{6} \mathrm{~A}$ modifications. Ban et al. found that METTL3 and METTL14 stabilize or even increase the expression of LNCAROD in HNSCC cells through $\mathrm{m}^{6} \mathrm{~A}$ modifications. LNCAROD binds to YBX1 and HSPA1A proteins, and its overexpression enhances the proliferation and migration of HNSCC cells. The dysregulation of $\mathrm{m}^{6} \mathrm{~A}$ methylation may cause abnormal expression of LNCAROD in HNSCC (Ban et al., 2020). In laryngeal squamous cell carcinoma (LSCC) patients, the expression of is significantly increased RBM15, indicating a poor prognosis. RBM15 mediates $\mathrm{m}^{6} \mathrm{~A}$ modifications of TMBIM6, and stabilizes the expression of TMBIM6 through IGF2BP3, thereby promoting LSCC (Wang et al., 2021b). Arumugam et al. reported that the expression levels of KIAA1429 in HNSCC tissues were significantly higher than in normal tissues. The increase of KIAA1429 expression is closely related to HNSCC metastasis. KIAA1429 (VIRMA), an $\mathrm{m}^{6} \mathrm{~A}$ writer, is frequently amplified and mutated (8\%), which promotes the overexpression of KIAA1429 mRNA. Therefore, the methylation level of KIAA1429 (VIRMA) may be closely related to HNSCC (Arumugam et al., 2021). Similarly, there is evidence that KIAA1429 is a highly expressed $\mathrm{m}^{6} \mathrm{~A}$ regulatory gene in HNSCC (Zhao and Cui, 2019; Paramasivam et al., 2021).
Unfortunately, these studies did not explore these relevant mechanisms in depth.

\section{N6-Methyladenosine Readers in Head and Neck Squamous Cell Carcinoma}

The IGF2BP family promotes tumor progression by reading $\mathrm{m}^{6} \mathrm{~A}$-modified oncogenic mRNA. IGF2BP2 plays a key role in the progression of many cancers. Studies have shown that the overexpression of IGF2BP2 predicts poor prognosis of patients with colorectal cancer, acute myeloid leukemia and metaplastic breast cancer (He et al., 2018; Wang et al., 2020a). Upregulation of IGF2BP2 in pancreatic cancer may influence cell proliferation through the PI3K/Akt signaling pathway (Xu et al., 2019b). It has been confirmed that SNPs in IGF2BP2 and IGF2BP3 promote lymph node metastasis in esophagogastric junction adenocarcinoma (Chen et al., 2018). IGF2BP2 has also been linked to the occurrence and development of head and neck carcinoma. Paramasivam et al. pointed out that nearly half of HNSCC patients show significant changes in $\mathrm{m}^{6} \mathrm{~A}$ regulatory genes (Paramasivam et al., 2021). Among the aforementioned patients, nearly half of the patients showed increased expression of IGF2BP2, and the expression of the most common oncogene in 
TABLE 1 | Regulation of $\mathrm{m}^{6} \mathrm{~A}$ modification in HNSCC.

\begin{tabular}{|c|c|c|c|c|}
\hline m6A Regulators & Target & $\begin{array}{l}\text { Regulation in } \\
\text { HNSCC }\end{array}$ & Function & Mechanisms \\
\hline \multirow[t]{2}{*}{$\begin{array}{l}\text { METTL3 Wu et al. (2021); Arumugam et al. } \\
\text { (2021); Ai et al. (2021) }\end{array}$} & Circux1 Wu et al. (2021) & Up & writer & $\begin{array}{l}\text { METTL3 promotes the m6A methylation level of Circux1 } \\
\text { and increases the stability of its expression in } \\
\text { hypopharyngeal squamous cell carcinoma (HPSCC) Wu } \\
\text { et al. (2021) }\end{array}$ \\
\hline & $\begin{array}{l}\text { PRMT5 and PD-L1 Ai et al. } \\
(2021)\end{array}$ & Up & writer & $\begin{array}{l}\text { METTL3 can promote the progress of OSCC by } \\
\text { increasing the m6A editing degree of PRMT5 and PD-L1 } \\
\text { Ai et al., } 2021\end{array}$ \\
\hline METTL3 and METTL14 & LNCAROD & Up & writer & $\begin{array}{l}\text { METTL3 and METTL14 can stabilize the expression of } \\
\text { LNCAROD in HNSCC cells through m6A modification } \\
\text { Ban et al., } 2020\end{array}$ \\
\hline RBM15 & TMBIM6 & Up & writer & $\begin{array}{l}\text { RBM15 mediates the m6A modification of TMBIM6 and } \\
\text { stabilizes the expression of TMBIM6 through } \\
\text { IGF2BP3 Wang et al. (2021b) }\end{array}$ \\
\hline KIAA1429 (VIRMA) & KIAA1429 & Up & writer & $\begin{array}{l}\text { KIAA1429 (VIRMA) can be used as a "writer" of m6A to } \\
\text { help overexpression of KIAA1429 mRNA Arumugam } \\
\text { et al., } 2021\end{array}$ \\
\hline $\begin{array}{l}\text { IGF2BP family (IGF2BP1, IGF2BP2 Geng et al., } \\
\text { 2021; Paramasivam et al., 2021, IGF2BP3) }\end{array}$ & $\begin{array}{l}\text { HMGA2 } \\
\text { TK1 } \\
\text { HDGF } \\
\text { FSCN1 } \\
\text { MKI67 } \\
\text { CD44 }\end{array}$ & Up & reader & $\begin{array}{l}\text { The IGF2BP family promotes tumor progression by } \\
\text { reading m6A-modified oncogenic mRNA Paramasivam } \\
\text { et al., } 2021\end{array}$ \\
\hline $\begin{array}{l}\text { YTHDF1 Ye et al., 2020; Zhou et al., } 2020 \\
\text { YTHDF2 Zhou et al., } 2020 \\
\text { YTHDF3 Arumugam et al., } 2021\end{array}$ & & Up & reader & $\begin{array}{l}\text { The YTHDF1 methyltransferase domain can bind to the } \\
3^{\prime} \cup T R \text { and } 5^{\prime} U T R \text { of TRFC mRNA to promote m6A } \\
\text { modification and translation of TFRC mRNA Ye et al., } \\
2020\end{array}$ \\
\hline YTHDC2 Zhou et al., 2020 & & & reader & \\
\hline ALKBH5 Shriwas et al., 2020 & $\begin{array}{l}\text { FOXM1, NANOG (Shriwas } \\
\text { et al., 2020) }\end{array}$ & Up & eraser & $\begin{array}{l}\text { DDX3 directly regulates ALKBH5 to eliminate m6A } \\
\text { methylation in the new transcripts of FOXM1 and } \\
\text { NANOG Shriwas et al., } 2020\end{array}$ \\
\hline
\end{tabular}
2021

GRHL3-AS1, AL121845.4, Down

GRHL3-AS1, AL121845.4, AC116914.2, AL513190.1 AC116914.2, AL513190.1

\begin{tabular}{|c|c|c|c|}
\hline Remedy & $\begin{array}{l}\text { Regulation of } \\
\text { target }\end{array}$ & Target & Mechanisms \\
\hline CRISPR/Cas9 (HuR-CRISPR) & Knockout & HuR (ELAVL1) & $\begin{array}{l}\text { The multifunctional nanoparticles Wang et al. designed can achieve targeted delivery of HuR } \\
\text { CRISPR and epirubicin, and significantly improved the symptoms of mice bearing SAS tumors } \\
\text { Wang et al. (2021a) }\end{array}$ \\
\hline CRISPR-dCas9 & Reactivate & ZAR1 & $\begin{array}{l}\text { Epigenetic therapy through the CRISPR-dCas9 method can accurately target and reactivate } \\
\text { zygote arrest } 1 \text { (ZAR1), allowing it to regain its role as a tumor suppressor Deutschmeyer and } \\
\text { Richter, (2020) }\end{array}$ \\
\hline $\begin{array}{l}\text { Immune Checkpoint Inhibitor } \\
\text { (TIGIT) }\end{array}$ & Block & CD155 & $\begin{array}{l}\text { Blocking TIGIT/CD155 combined with PD-L1 monoclonal antibody treatment can significantly } \\
\text { improve the efficacy of HNSCC Mao et al., } 2021\end{array}$ \\
\hline Immune Checkpoint Inhibitor & Conjunct & P53 & $\begin{array}{l}\text { Adenoviral p53 can work in conjunction with immune checkpoint inhibitors to jointly exert anti- } \\
\text { cancer effects Sobol et al., } 2021\end{array}$ \\
\hline Immune Checkpoint Inhibitor & Inhibition & PD-1/ PD-L1 & ICls have good anti-tumor activity against R/M HNSCC Lee et al., 2021 \\
\hline Type I interferon & Promote & ADAR1 & $\begin{array}{l}\text { Type I interferon treatment can increase the amount and degree of RNA editing in esophageal } \\
\text { squamous cell carcinoma cell lines Zhang et al., } 2017\end{array}$ \\
\hline anti-OX40 neoadjuvant & Activate & $\begin{array}{l}\mathrm{CD}^{+} \text {and } \mathrm{CD}^{+} \\
\mathrm{T} \text { cell }\end{array}$ & $\begin{array}{l}\text { Patients with advanced HNSCC can receive anti-OX40 neoadjuvant treatment before surgery, } \\
\text { which is not only safe, but can also increase the activation and proliferation of CD4 }{ }^{+} \text {and CD8 } \\
\text { T cells in the blood and tumors Duhen et al., } 2021\end{array}$ \\
\hline
\end{tabular}

HNSCC patients increased with higher levels of IGF2BP2. Similarly, Geng et al. reported that IGF2BP2 is increased in HNSCC and serves as an $\mathrm{m}^{6} \mathrm{~A}$ regulatory gene (Geng et al.,
2021). This shows that IGF2BP2 is closely related to the occurrence and development of HNSCC. Deng et al. showed that IGF2BP2 is upregulated in HNSCC tissues, and its high 
expression is associated with poor prognosis, playing a key role in HNSCC progression (Deng et al., 2020). Wang et al. also found that IGF2BP2 is highly expressed in papillary thyroid cancer (PTC) tissues and is closely related to the poor prognosis of PTC patients. The risk score of the $\mathrm{m}^{6} \mathrm{~A}$-related IGF2BP2 signature can be used as an independent prognostic factor of PTC, which helps predict the disease-free survival of PTC patients (Wang et al., 2020d). This evidence indicates that the IGF2BP family may act as a key regulatory node, positively regulating the pathogenesis of HNSCC through $\mathrm{m}^{6} \mathrm{~A}$ methylation modifications.

A recent study showed that the $\mathrm{m}^{6} \mathrm{~A}$ reader $\mathrm{YTH}$ N6methyladenosine RNA-binding protein 1 (YTHDF1) promotes the degradation of BZLF1 and BRLF1 by recruiting the RNA degrading proteins ZAP, DDX17 and DCP2. YTHDF1 ultimately inhibits EBV infection and lytic replication. This process is dependent on XRN1. Xia et al. speculated that EBV introduces $\mathrm{m}^{6} \mathrm{~A}$ modifications into host cells to destabilize BZLF1 and BRLF1, thereby inhibiting lytic replication and maintaining the incubation period of the virus (Xia et al., 2021). Previously, Ye et al. demonstrated that high expression of YTHDF1 increases $\mathrm{m}^{6} \mathrm{~A}$ modifications on TFRC mRNA to promote iron accumulation in hypopharyngeal squamous cell carcinoma (HPSCC). These modifications on TFRC mRNA have also influence tumor occurrence and proliferation. At the same time, YTHDF1 and iron-related genes (FTH1 and TFRC) are significantly upregulated in tumor tissues (Ye et al., 2020). Therefore, YTHDF1 may serve as a potential therapeutic target for HNSCC.

YTHDC2 is an $\mathrm{m}^{6} \mathrm{~A}$ reader protein (Kretschmer et al., 2018). It is a tumor suppressor gene reduced in HNSCC tissues that is closely associated with prognosis and immune infiltration levels (Li et al., 2020a).

\section{N6-Methyladenosine Erasers in Head and Neck Squamous Cell Carcinoma}

Only two $\mathrm{m}^{6} \mathrm{~A}$ erasers, including FTO and ALKBH5, have been uncovered so far (Zhao and Cui, 2019; Zhou et al., 2020; Paramasivam et al., 2021). FTO, a $\mathrm{m}^{6} \mathrm{~A}$ demethylase associated with human obesity, reverses $\mathrm{m}^{6} \mathrm{~A}$ modifications (Jia et al., 2011). Shriwas et al. found that the $\mathrm{m}^{6} \mathrm{~A}$ demethylase ALKBH5 is directly regulated by the DEAD-box RNA helicase 3 (DDX3), erasing $\mathrm{m}^{6} \mathrm{~A}$ methylation in new FOXM1 and NANOG transcripts and causes chemotherapy resistance (Shriwas et al., 2020). FTO regulates the proliferation and migration of cervical cancer cells by modifying E2F1 and Myc transcripts (Zou et al., 2019). However, there is no related work investigating the role of FTO as an $\mathrm{m}^{6} \mathrm{~A}$ eraser in HNSCC.

\section{Bioinformatics Reveal N6-Methyladenosine Methylation Regulatory Genes}

Of the expression of many $\mathrm{m}^{6} \mathrm{~A}$ regulatory genes, including writers (METTL3, METTL14, WTAP, ZC3H13 and RBM15), erasers (ALKBH5 and FTO), and readers (YTHDF1, YTHDF2, YTHDF3, YTHDC1, IGF2BP1 and IGF2BP3) were found to be significantly increased in HNSCC tissues (Feng et al., 2021; Paramasivam et al., 2021). Deng et al. pointed out that the expression of $\mathrm{m}^{6} \mathrm{~A}$ methylation regulatory genes is significantly related to the prognosis of HNSCC (Deng et al., 2021). Zhou et al. identified $10 \mathrm{~m}^{6} \mathrm{~A}$ regulators and those high expression levels of ALKBH5, FTO, METTL14, WTAP, YTHDC1, YTHDF1 and YTHDF2 predict poor prognosis for HNSCC patients. The expression level of YTHDC2 was also found to be directly proportional to patient prognosis (Zhou et al., 2020). However, this study also performed a preliminary analysis and further studies are needed. Feng et al. used bioinformatic methods to screen $4 \mathrm{~m}^{6} \mathrm{~A}$-modified differentially expressed lncRNAs between high-risk group and low-risk group cancer groups. Interestingly, results showed that the expression levels of these four $\mathrm{m}^{6} \mathrm{~A}$-modified $\operatorname{lncRNAs}$ were reduced in the high-risk group. The higher the $\mathrm{m}^{6} \mathrm{~A}$-modified lncRNA expression level, the higher the survival rate of HNSCC patients. In other words, these four $\mathrm{m}^{6} \mathrm{~A}$-modified lncRNAs showed protective effects for HNSCC patients (Feng et al., 2021). This finding differs from public opinion, but indicates that the biological role of $\mathrm{m}^{6} \mathrm{~A}$ methylation modifications in HNSCC requires further exploration. Other relevant bioinformatic analyses show similar findings (Zhao and Cui, 2019; Li et al., 2020a; Huang et al., 2020). These studies identified key genes as potential aspects for future research and treatment (Yi et al., 2020).

\section{The Role of $\mathbf{N}^{1}$-Methyladenosine in Head and Neck Squamous Cell Carcinoma}

There are limited studies investigating the role of $\mathrm{m}^{1} \mathrm{~A}$ modifications in cancer as well its role in HNSCC. Some studies revealed that $\mathrm{m}^{1} \mathrm{~A}$ methylation modifications influence different cancers including hepatocellular carcinoma (HCC), lung cancer, colorectal cancer and pancreatic cancer (Wang et al., 2020; Shi et al., 2020; Xie et al., 2020). In addition, Li et al. found that expression of $\mathrm{m}^{1} \mathrm{~A}$ regulatory factors are significantly altered in cancer patients and are closely related to changes in carcinogenic pathways and overall survival rate (Li et al., 2021).

Zhao et al. comprehensively analyzed TCGA data for diagnosed with esophageal carcinoma (ESCA), liver hepatocellular carcinoma (LIHC), stomach adenocarcinoma (STAD), pancreatic adenocarcinoma (PAAD) and colorectal adenocarcinoma (COAD)). Expression of $\mathrm{m}^{1} \mathrm{~A}$ regulators, such as writers (TRMT6, TRMT61A and TRMT10C), erasers (ALKBH1, ALKBH3) and readers (YTHDF1-3, YTHDC1), were significantly changed in all gastrointestinal cancers analyzed.

The expression levels of $\mathrm{m}^{1} \mathrm{~A}$ regulatory genes are significantly higher in HCC than in normal tissues. In addition, the expression levels of TRMT6, TRMT61A and TRMT10C, as well as ALKBH3 and YTHDF2, are higher in patients with late-stage tumors (G1G3) (Zhao et al., 2019). Shi et al. also found that the expression of $\mathrm{m}^{1} \mathrm{~A}$-related regulatory genes, such as TRMT6, TRMT61A, TRMT10C and YTHDF1, are helpful in assessing risk and survival prediction of HCC patients. A significant correlation between YTHDF1 and TRMT6 was identified in their study. 
YTHDF1, which acts as $\mathrm{m}^{6} \mathrm{~A}$ modification reader, also acts as $\mathrm{m}^{1} \mathrm{~A}$ modified RNA binding protein, playing an important role in regulating $\mathrm{m}^{1} \mathrm{~A}$ methylation modifications. TRMT6 forms a methyltransferase complex with TRMT61A to catalyze the methylation of the $\mathrm{N}^{1}$ position of adenosine residues in mRNAs. Increased expression of TRMT6 is associated with poor prognosis (Shi et al., 2020). Meanwhile, Zhao et al. found that some GC patients show alterations in $\mathrm{m}^{1} \mathrm{~A}$ regulatory factors, including mutations, copy number amplifications or deep deletions. The change frequency of TRMT6 is nearly $1.8 \%$, and the mutation frequency of the YTHDF1 and YTHDF3 readers is highest amongst GC patients, reaching 6 and 5\%, respectively (Zhao et al., 2019). This is consistent with findings by Shi et al. Their studies revealed that copy number variations $(\mathrm{CNV})$ have a higher frequency in $\mathrm{m}^{1} \mathrm{~A}$-related regulatory genes. The differential expression of $10 \mathrm{~m}^{1} \mathrm{~A}$-related regulatory genes, such as the reader YTHDF1, can be used as prognostic indicators (Shi et al., 2020). Based on these observations, there is reason to believe that YTHDF1 can be used as a reader along with TRMT6 and TRMT61A to jointly regulate $\mathrm{m}^{1} \mathrm{~A}$ methylation in HCC. Interestingly, Wang et al. also observed dysregulation in $\mathrm{m}^{1} \mathrm{~A}$ regulatory factors in gynecological cancers. TRMT10C was found to be highly expressed in ovarian and cervical cancers and being associated with a poor prognosis. TRMT10C inhibits the proliferation and migration of ovarian and cervical cancer cells (Wang et al., 2020c). Therefore, it is reasonable to believe that TRMT10C can also be used as a biomarker for predicting the prognosis of patients with gynecological cancers. $\mathrm{m}^{1} \mathrm{~A}$ modification-related genes may affect the expression of oncogenes through $\mathrm{m}^{1} \mathrm{~A}$ methylation and may be involved in the progression of HNSCC.

These differences are also present in PAAD but only at a moderate level compared with HCC (Shi et al., 2020). Zheng et al. also found that changes of $\mathrm{m}^{1} \mathrm{~A}$ regulatory genes in PAAD are associated with cancer stage. Some of these genes serve as writers or readers and have a high mutational frequency. $\mathrm{CNV}$ has also been found to have a high frequency of mutations. Meanwhile, changes in the YTHDF1 and TRMT61A genes were found in two PAAD samples. Even though high expression levels of YTHDF1 and YTHDF2 were found to be associated with the poor prognosis of PAAD patients (Chen et al., 2017a), it is not clear whether this is due $\operatorname{tom}^{1} \mathrm{~A}$ regulation. The $\mathrm{m}^{1} \mathrm{~A}$-related writers, erasers and readers are differentially expressed depending on the stage. Low expression of the ALKBH1 eraser predicts poor prognosis of PAAD patients (Zheng et al., 2021). ALKBH1 contains both $\mathrm{m}^{1} \mathrm{~A}$ and $\mathrm{m}^{6} \mathrm{~A}$ demethylase activities (Wu et al., 2016; Kawarada et al., 2017). Wang et al. found that ALKBH1, YTHDF1, TRMT6, TRMT10C and TRMT61B are elevated in endometrial cancers (Wang et al., 2020c). Therefore, overexpression of ALKBH1 most likely reverses methylation and inhibits tumor development. Shi et al. identified that $\mathrm{m}^{1} \mathrm{~A}$ modifications are increased in COAD tissues, accompanied by down-regulation in lncRNA expression levels relative to normal adjacent tissues (Shi et al., 2021). Meanwhile, three different $\mathrm{m}^{1} \mathrm{~A}$ modification patterns identified by Gao et al. significantly affect relapse-free survival, overall survival and the number of tumor microenvironment infiltration cells in COAD patients. In addition, Pan et al. found that $\mathrm{m}^{1} \mathrm{~A}$ regulatory factor expression levels significantly differed between lung squamous cell carcinoma and normal tissues (Pan et al., 2021).

This evidence proves that $\mathrm{m}^{1} \mathrm{~A}$ methylation modifications play important roles in gastrointestinal, gynecological and lung cancers. $\mathrm{m}^{1} \mathrm{~A}$ methylation modifications also influence the occurrence and development of HNSCC.

\section{The Role of Alternative Polyadenylation in Head and Neck Squamous Cell Carcinoma}

APA induces $3^{\prime}$-UTR shortening and it has been considered a specific feature of tumorigenesis and involved in the development of HNSCC.

CPSF plays an important role in processing the $3^{\prime}$-processing complex. Core $3^{\prime}$-processing factors include protein complexes (CPSF, CSTF, CFI and CFII) and several single proteins. CPSF1 is the largest subunit of the protein complex (Murthy and Manley, $1995)$ that recognizes polyadenylation signals and regulates APA (Martin et al., 2012; MacDonald, 2019). Sakai et al. identified 13 candidate spliceosome genes significantly altered in HNSCC. In these candidate genes, a higher number of alternative splicing events (ASEs) were identified with CPSF1 was overexpressed. This promoted the growth of HNSCC cells. In addition, junction analysis showed that abnormal expression of CPSF1 is related to ASEs of cancer-related genes, such as LAMC2, UBE2C, AKT2, AKT2, BOK, MAP4 and FANCD2. Therefore, it was speculated that CPSF1 overexpression leads to abnormal splicing of oncogenes and promotes tumor occurrence and development (Sakai et al., 2020). Interestingly, there is evidence that CPSF1 promotes tumor development by regulating APA events in triplenegative breast cancer (TNBC). Wang et al. determined that CPSF1 and PABPN1 are the main C/P factors that regulate APA events. Knockout of CPSF1 or PABPN1 reverses APA events of tumor-related genes in TNBCs, inhibits tumor cell proliferation, promotes apoptosis and redistributes the cell cycle (Wang et al., 2020b). This indicates that the mechanism by which APA regulates TNBC cell proliferation may be achieved by changing core processing factor (CPSF1 and PABPN1) levels. We speculate that CPSF1 may affect tumors development and group through the APA pathway.

PABPN1 may also act as the core factor of APA regulation. Poly (A) tails grow to $\sim 250$ nucleotides. PABPN1 binds to poly (A) and breaks the connection between CPSF and poly (A) polymerase, thereby controlling the length of the poly (A) tail (Wahle, 1995; Kuhn et al., 2009; Eckmann et al., 2011). Xiang et al. proved that PABPN1 is a key factor regulating the APA profile of many cancers (Xiang et al., 2018). Ichinose et al. found that PABPN1 acts as an APA inhibitor. Deletion of PABPN1 induces APA events, leading to microRNA-mediated gene regulation and causing the release of cancer cells (Ichinose et al., 2014). In summary, we speculate that CPSF1 and PABPN1 serve as key regulatory factors to increase APA events and promote HNSCC development.

In addition, we believe that some oncogenes alter the length of $3^{\prime}$-UTR through APA events, thereby evading gene suppression and promoting the growth of HNSCC (Martin et al., 2012; Missan 
et al., 2015). It has been demonstrated in NPC that the oncogene FND3CB increases proximal polyadenylation sites through APA events, resulting in shorter $3^{\prime}$-UTRs. This evades miRNAmediated gene suppression ( $\mathrm{Li}$ et al., 2020b). The same mechanism of action has also been identified in bladder cancer (Xiong et al., 2019) and HCC (Sun et al., 2017; Tan et al., 2018). Meanwhile, 195 genes were also identified in NPC and their tandem $3^{\prime}$-UTR lengths were significantly different between NPC and the control group (Xu et al., 2018). In esophageal squamous cell carcinomas, 903 genes related to adhesion junctions and the cell cycle shortened the $3^{\prime}$-UTR, and the distal PolyA site was used by 917 genes (Sun et al., 2014). This difference may be caused by APA-mediated gene expression regulation. In summary, APA may play a key role in the occurrence and development of HNSCC.

\section{The Role of Adenosine-to-Inosine Editing in Head and Neck Squamous Cell Carcinoma} Currently, there are only a few studies directly investigating A-toI RNA editing in HNSCC. One reason for this may be due to limited detection technology in identifying A-to-I editing sites. Previous studies have shown A-to-I RNA editing (R334G) in the tumor suppressor gene prox 1 present in 4 of 8 esophageal cancer cases, indicating that A-to-I RNA editing may be closely related to the progression of this cancer (Yoshimoto et al., 2007). Hochberg et al. identified two A-to-I editing sites in insulin-like growth factor-binding protein-7 (IGFBP7) transcripts. In the normal epidermis, IGFBP7 transcripts are highly edited, but this editing is significantly reduced in basal cell and squamous cell carcinomas. Edited IGFBP7 inhibits the proliferation of keratinocytes and induces their senescence. These results indicate that A-to-I RNA editing in IGFBP7 maintains the balance between normal skin proliferation and aging, and its reduction may promote the occurrence and development of carcinoma (Hochberg et al., 2013). A recent study showed that A-to-I SLC22A3 RNA editing resulted in a decrease in SLC22A3 gene expression and led to lymph node metastasis in ESCC cases. This process almost only occurs in familial high-risk individuals, making them susceptible to ESCC, but does not occur in sporadic ESCC cases. The A-to-I transcript editing event (A261 at exon 1) that resulted in the substitution of asparagine (Asn)-aspartate (Asp) amino acids may be related to ESCC susceptibility (Fu et al., 2017). However, this study later discovered that the RNA editing enzyme ADAR2 is a familial ESCC susceptibility gene, suggesting that ADAR plays a central role in A-to-I RNA editing. Adenosine deaminase catalysis that acts on the RNA (ADARs) family plays an important role in A-to-I RNA editing. Therefore, most current research is focused on ADARs.

\section{ADAR1 as a Foe}

ADAR1 may be closely related to the occurrence and development of HNSCC. Zhang et al. showed that ADAR1 expression is related to STAT1, STAT2 and IRF9, and the abundance of ADAR1 protein is related to the activation of JAK/STAT pathway induced by type I interferons. The activation of JAK/STAT pathway regulates the expression of
ADAR1, which leads to an abnormal RNA editing spectrum in ESCC (Zhang et al., 2017). Interestingly, Qin et al. found that ADAR1 was overexpressed in ESCC and that it predicted a poor prognosis. Over-editing of AZIN1 information catalyzed by ADAR1 makes carcinomas more aggressive. This study confirmed that ADAR1 can be used as an oncogene, and the excessive A-to-I editing mediated by it promotes the development of ESCC (Qin et al., 2014). In summary, ADAR1 may be closely related to the occurrence and development of ESCC. A-to-I RNA editing mediated by ADAR1 may promote ESCC. In addition, there is evidence that ADAR1 plays an important biological function in oral squamous cell carcinoma (OSCC). Liu et al. found that ADAR1 is over-expressed in OSCC and positively correlates with migration, invasion and EMT. ADAR1 may combine with dicer to increase the expression of oncogenic miRNAs, affect cell migration and invasion, promote carcinoma growth and reduce patient survival (Bo et al., 2019). Ma et al. found that ADAR binds to forkhead box D1 antisense RNA 1 (FOXD1-AS1) and FOXD1 in OSCC cells, to enhances the stability of FOXD1 mRNA, thereby promoting the occurrence and development of OSCC (Ma et al., 2021). This evidence indicates that ADAR1 is involved in A-to-I RNA editing to promote the occurrence and development of HNSCC. An increase in A-to-I RNA editing will lead to increased proliferation and migration, which indicates a poor prognosis for HNSCC patients.

\section{ADAR2: Friend or Foe?}

Behm et al. found that mice do not survive to adulthood in the absence of the active editing enzymes ADAR1 or ADAR2. As neurons mature, the number of interactions between ADAR2 and nuclear isomerase Pin1 increases, which contributes to the stability of ADAR2 protein and helps mouse neurons develop and mature (Behm et al., 2017). Terajima et al. showed that ADAR2 mediated A-to-I RNA editing critically contributes to light induced circadian clock phase shifts in the suprachiasmatic nucleus of the mouse hypothalamus (Terajima et al., 2018). However, Agranat et al. identified arginine/glycine sites of SON mRNA as ADAR2 dependent sites. They also detected multiple circular RNAs with ADAR2 dependent sites in SHSY5Y cells and culture medium. These RNAs with ADAR2 dependent sites may serve as biomarkers for amyotrophic lateral sclerosis (Agranat et al., 2010). As previously mentioned, Fu et al. determined that ADAR2 is a familial ESCC susceptibility gene and that SLC22A3 is a tumor suppressor gene. ADAR2 is overexpressed in familial normal esophageal tissues, which increases the A-to-I RNA editing of the SLC22A3 gene and reduces the expression of the SLC22A3 gene, thereby increasing the susceptibility of ESCC (Fu et al., 2017). Interestingly, Chen et al. believe that overexpression of ADAR2 inhibits the growth and induces apoptosis by editing and stabilizing IGFBP7 in ESCC. Knockout of ADAR2 in carcinoma cells with high expression of ADAR2 inhibits tumor cell apoptosis (Chen et al., 2017d). This is contrary to the view of Fu et al., which suggests that overexpression of ADAR2 promotes tumor growth (Fu et al., 2017). Therefore, additional studies are needed to identify the true roles of ADAR2. 


\section{ADAR3: A Potential Friend}

The biological role of ADAR3 has been studied over recent years. Wang et al. found that ADAR3 binds to two activity-dependent immediate-early genes in response to brain stimulation that encode the $3^{\prime}$-UTRs of the mRNAs early growth response 1 (EGR1) and bispecific phosphatase 1 (DUSP1), thereby regulating the transcription levels of DUSP1 and EGR1. This result suggests that $A D A R 3$ may play a new role in brain function (Wang et al., 2019b). ADAR3 was also found to be related to Q/R locus editing. The $\mathrm{Q} / \mathrm{R}$ site refers to the codon modification site of the glutamate receptor ionotropic AMPA 2 (GRIA2). GRIA2 is an adenosine in glutamate receptor subunit $\mathrm{B}$ transcripts. In glioblastoma, the reduction of GRIA2 transcript editing leads to cell migration and tumor invasion. However, Oakes et al. detected that ADAR3 expression was higher in glioblastoma compared to adjacent brain tissues. Meanwhile, they found that ADAR3 directly binds to GRIA2 precursor-mRNAs in astrocytes and astrocytoma cell lines. Overexpression of ADAR3 inhibits the RNA editing of the GRIA2 Q/R site, thus inhibiting tumor migration (Oakes et al., 2017). Interestingly, ADAR3 was also found to negatively correlate with the prognosis of low-grade gliomas, and positively correlate with GRIA2 (Q607R) editing. Zhang et al. believe that ADAR3 may inhibit the growth of glioma cells, and its high expression serves as a prognosis for patients with low-grade gliomas (Zhang et al., 2018). Therefore, the presence of ADAR3 may indicate a good prognosis for cancer patients.

\section{ADENINE-RELATED RNA MODIFICATIONS AND HEAD AND NECK SQUAMOUS CELL CARCINOMA THERAPY}

The current treatment methods for HNSCC mainly include a combination of surgery, radiotherapy, chemotherapy, organsparing neoadjuvant radiotherapy and chemotherapy. There is an extreme treatment plan for recurrent or metastatic HNSCC (R/M HNSCC) cases that combines platinum, fluorouracil and cetuximab chemotherapy (Vermorken et al., 2008). This can increase the survival rate of patients (the risk of death ratio (HR) is 0.80, $p=0.04$ ) (Leon et al., 2005; Stewart et al., 2009; Vermorken et al., 2014), but the efficacy of R/M HNSCC patients who are resistant to platinum-containing chemotherapy is limited. Also, many patients cannot tolerate the side effects caused by radiotherapy and chemotherapy. Therefore, it is necessary to find new immunotherapy targets.

$\mathrm{HuR}$ (ELAVL1) is an RNA-binding protein that plays a positive role in regulating tumor survival and invasion. Wang et al. proposed that knockout of HuR through CRISPR/Cas9 (HuR-CRISPR) inhibits tumor progression. Multifunctional nanoparticles can achieve targeted delivery of HuR CRISPR and epirubicin, and significantly improved the symptoms of mice bearing SAS tumors (Wang et al., 2021a). However, related research is still at the stage of animal experiments, and further research is needed to determine whether it can be applied to the clinic.

Programmed cell death protein-1 (PD-1/CD279) is an important immune checkpoint expressed by $\mathrm{T}$ cells. It can be coupled with the programmed death ligand PD-L1 (B7-H1/ CD274) expressed by tumor cells and inhibit the activation of $\mathrm{T}$ cells and the anti-tumor response, evading immune system clearance. Immune checkpoint inhibitors (ICIs) can block the inhibitory immune checkpoint pathway, thereby reactivating anti-tumor immune activity. Common ICIs include PD-1/PDL1 inhibitors that can specifically bind to PD-L1 on tumor cells and block the inhibitory immune checkpoint pathway (Gong et al., 2018). TIGIT is a new immune checkpoint molecule that binds to CD155 with high affinity (Yu et al., 2009). It can deliver immunosuppressive signals by binding to CD155 in competition with CD226 (dNaM-1). Liang et al. showed that CD155 (+) PDL1 ( + ) bone marrow mesenchymal stem cells are enriched in the tumor microenvironment. Blocking TIGIT/CD155 combined with PD-L1 monoclonal antibody treatment can significantly improve the efficacy of HNSCC (Mao et al., 2021). Meanwhile, Liu et al. proposed that the expression of PD-L1 in HNSCC cytology samples is highly consistent with matched histological samples (Liu et al., 2021). Lee et al. also believe that ICIs show good anti-tumor activity against R/M HNSCC (Lee et al., 2021). Therefore, ICIs can be used for the treatment of HNSCC, and PD1/PD-L1 inhibitors may play a positive role in promoting this treatment.

In addition, there are other immunotherapy approaches for HNSCC, such as p53 targeted therapy. Adenoviral p53 can work in conjunction with immune checkpoint inhibitors to jointly exert anti-cancer effects (Sobol et al., 2021). Type I interferon treatment can increase the amount and degree of RNA editing in ESCC cell lines (Zhang et al., 2017). Epigenetic therapy using the CRISPR-dCas 9 method accurately targets and reactivates zygote arrest 1 (ZAR1), allowing it to regain its role as a tumor suppressor (Deutschmeyer and Richter, 2020). Patients with advanced HNSCC can receive anti-OX40 neoadjuvant treatment before surgery. It not only is safe, but can also increase the activation and proliferation of $\mathrm{CD}^{+}$and $\mathrm{CD} 8^{+}$ $\mathrm{T}$ cells in the blood and tumors (Duhen et al., 2021) (Table 2). Therefore, we have reason to believe that the future treatment of HNSCC will be more accurate and effective.

\section{DISCUSSION}

RNA editing refers to post-transcriptional changes in RNA sequences. RNA modifications play key roles in the occurrence of various cancers, but the specific mechanisms are still unclear. These modifications may act as tumor-promoting factors to promote tumor growth, while it can also be used as inhibitors to limit the occurrence of tumors.

Presently, RNA editing research in HNSCC can be summarized into the following four mechanisms: 1) The number of RNA editing changes. An increase in the number of RNA edits can be observed in some cancers, but it does not cause overexpression of oncogenes. The may be due to the presence of these editing sites in normal tissues as well (Takahashi et al., 2006; Chen et al., 2013). 2) So far, most reported RNA edits are located in introns and $3^{\prime}$-UTRs, and there is almost no RNA edits present in the coding region (Zhang et al., 2016; Liu et al., 2019). These transcriptional "noises," once 
thought to have no biological functions, have been shown to play a key role in some biological activities of eukaryotes, such as chromatin modification, post-transcriptional processing and nuclear transport (Ponting and Belgard, 2010; Nagano and Fraser, 2011; Lee, 2012; Shi et al., 2013). Some studies related to APA events have shown that some oncogenes have changes in the length of $3^{\prime}$-UTRs through APA events, thereby avoiding gene suppression and promoting tumor occurrence. A study reveals that $\mathrm{m}^{6} \mathrm{~A}$ demethylase ALKBH5 is directly regulated by DDX3 which leads to decreased $\mathrm{m}^{6} \mathrm{~A}$ methylation in FOXM1 and NANOG nascent transcript that contribute to chemoresistance (Shriwas et al., 2020). This mode of RNA editing has been studied (Murthy and Manley, 1995; Sun et al., 2014; Missan et al., 2015; Sun et al., 2017; Li et al., 2020b). 3) Even though tumor samples show simultaneous increases or decreases in RNA editing levels, changes in RNA editing in specific sites related to tumorigenesis show the opposite trend (Han et al., 2015; Paz-Yaacov et al., 2015). For example, breast cancer shows a significant increase in RNA editing at the transcriptome level, but in the specific editing sites affecting breast cancer, the RNA editing drops below $10 \%$ (Fumagalli et al., 2015). IGFBP7 transcripts are highly edited in the normal epidermis, while this editing is significantly reduced in basal cell and squamous cell carcinomas (Hochberg et al., 2013); 4) A-to-I is regulated by the ADAR enzyme RNA editing, thereby regulating the editing level of oncogenes and regulating the development of cancer (Qiao et al., 2014; Chen et al., 2017c; Chen et al., 2017d; Dong et al., 2018; Caponio et al., 2019; Yu et al., 2019). For example, ADAR1 can mediate the increase of A-to-I editing, resulting in overediting of AZIN1 and promoting the development of ESCC (Qin et al., 2014).

In summary, recent studies have revealed RNA editing events in HNSCC. However, there is still very little known about the specific mechanisms of RNA modification to control cancer progression and drug resistance. Currently, investigators have been able to study the editing of non-coding regions using high throughput sequencing technology. At the same time, they have also found that non-coding regions have the highest levels of complexity. As a result, we started to explore the expression regulation of miRNAs and IncRNAs from a new perspective. This

\section{REFERENCES}

Agranat, L., Sperling, J., and Sperling, R. (2010). A Novel Tissue-specific Alternatively Spliced Form of the A-To-I RNA Editing Enzyme ADAR2. RNA Biol. 7, 253-262. doi:10.4161/rna.7.2.11568

Ai, Y., Liu, S., Luo, H., Wu, S., Wei, H., Tang, Z., et al. (2021). METTL3 Intensifies the Progress of Oral Squamous Cell Carcinoma via Modulating the m6A Amount of PRMT5 and PD-L1. J. Immunol. Res. 2021, 6149558. doi:10.1155/2021/6149558

Anderson, J., Phan, L., and Hinnebusch, A. G. (2000). The Gcd10p/Gcd14p Complex Is the Essential Two-Subunit tRNA(1-methyladenosine) Methyltransferase of Saccharomyces cerevisiae. Proc. Natl. Acad. Sci. U S A. 97, 5173-5178. doi:10.1073/pnas.090102597

Arumugam, P., George, R., and Jayaseelan, V. P. (2021). Aberrations of m6A Regulators Are Associated with Tumorigenesis and Metastasis in Head and Neck Squamous Cell Carcinoma. Arch. Oral Biol. 122, 105030. doi:10.1016/ j.archoralbio.2020.105030

Ban, Y., Tan, P., Cai, J., Li, J., Hu, M., Zhou, Y., et al. (2020). LNCAROD Is Stabilized by m6A Methylation and Promotes Cancer Progression via Forming new concept breaks traditional thinking, which believes that unedited sequences or biomarkers must be linked to downstream targets through certain mechanisms. The mechanism by which RNA editing regulates the occurrence and development of cancer is still unclear. Research on the pathophysiological functions of RNA modifications in cancer is still in the early stages of research and there is still a long way to go. However, there is increasing evidence that the dysregulation of RNA editing central mediators (such as ADAR) contributes to the progression of cancer. Therefore, future work should focus on how to translate these modifications into available treatment options and how to relate these modifying behaviors to diagnosis and prognosis.

\section{AUTHOR CONTRIBUTIONS}

$\mathrm{J}-\mathrm{YZ}$ and HS conceived and designed the study. X-XH, S-JW, M-DL, H-XG and X-TQ collected data and aided in writing the manuscript. HS, HY, MW and Y-FZ edited the manuscript. All authors read and approved the final manuscript.

\section{FUNDING}

This study was supported by the National Natural Science Foundation of China (No. 81802103, 81803938), Project of High-Level Talents in AHUTCM (Project code: 2019rcZD001), Excellent Young Scholars Project of Natural Science Foundation of Anhui Province in China(Grant Nos.2108085Y29), Open project of the Key Laboratory of Regenerative Biology, Chinese Academy of Sciences and Opening Project of Zhejiang Provincial Preponderant and Characteristic Subject of Key University (Chinese Traditional Medicine), Zhejiang Chinese Medical University (No.ZYXZD2019004). We thank the study participants and research staff for their contributions and commitment to this study. Figures are created with BioRender.com.

a Ternary Complex with HSPA1A and YBX1 in Head and Neck Squamous Cell Carcinoma. Mol. Oncol. 14, 1282-1296. doi:10.1002/1878-0261.12676

Bass, B. L. (2002). RNA Editing by Adenosine Deaminases that Act on RNA. Annu. Rev. Biochem. 71, 817-846. doi:10.1146/annurev.biochem.71.110601.135501

Behm, M., Wahlstedt, H., Widmark, A., Eriksson, M., and Öhman, M. (2017). Accumulation of Nuclear ADAR2 Regulates Adenosine-To-Inosine RNA Editing during Neuronal Development. J. Cel Sci 130, 745-753. doi:10.1242/ jcs. 200055

Berkovits, B. D., and Mayr, C. (2015). Alternative 3' UTRs Act as Scaffolds to Regulate Membrane Protein Localization. Nature 522, 363-367. doi:10.1038/ nature 14321

Bo, R., Liu, Z., Zhang, J., Gu, P., Ou, N., Sun, Y., et al. (2019). Mechanism of Lycium Barbarum Polysaccharides Liposomes on Activating Murine Dendritic Cells. Carbohydr. Polym. 205, 540-549. doi:10.1016/j.carbpol.2018.10.057

Caponio, V. C. A., Troiano, G., Botti, G., Pedicillo, M. C., Lo Russo, L., Mastrangelo, F., et al. (2019). Overexpression of ADAR1 into the Cytoplasm Correlates with a Better Prognosis of Patients with Oral Squamous Cells Carcinoma. J. Oral Pathol. Med. 48, 108-114. doi:10.1111/jop.12808

Chen, C. X., Cho, D. S., Wang, Q., Lai, F., Carter, K. C., and Nishikura, K. (2000). A Third Member of the RNA-specific Adenosine Deaminase Gene Family, 
ADAR3, Contains Both Single- and Double-Stranded RNA Binding Domains. RNA 6, 755-767. doi:10.1017/s1355838200000170

Chen, J., Sun, Y., Xu, X., Wang, D., He, J., Zhou, H., et al. (2017a). YTH Domain Family 2 Orchestrates Epithelial-Mesenchymal Transition/proliferation Dichotomy in Pancreatic Cancer Cells. Cell Cycle 16, 2259-2271. doi:10.1080/15384101.2017.1380125

Chen, L., Li, Y., Lin, C. H., Chan, T. H., Chow, R. K., Song, Y., et al. (2013). Recoding RNA Editing of AZIN1 Predisposes to Hepatocellular Carcinoma. Nat. Med. 19, 209-216. doi:10.1038/nm.3043

Chen, S., Qiu, H., Liu, C., Wang, Y., Tang, W., and Kang, M. (2018). Relationship between IGF2BP2 and IGFBP3 Polymorphisms and Susceptibility to Nonsmall-cell Lung Cancer: a Case-Control Study in Eastern Chinese Han Population. Cancer Manag. Res. 10, 2965-2975. doi:10.2147/CMAR.S169222

Chen, W., He, W., Cai, H., Hu, B., Zheng, C., Ke, X., et al. (2017b). A-to-I RNA Editing of BLCAP Lost the Inhibition to STAT3 Activation in Cervical Cancer. Oncotarget 8, 39417-39429. doi:10.18632/oncotarget.17034

Chen, Y., Wang, H., Lin, W., and Shuai, P. (2017c). ADAR1 Overexpression Is Associated with Cervical Cancer Progression and Angiogenesis. Diagn. Pathol. 12, 12. doi:10.1186/s13000-017-0600-0

Chen, Y. B., Liao, X. Y., Zhang, J. B., Wang, F., Qin, H. D., Zhang, L., et al. (2017d). ADAR2 Functions as a Tumor Suppressor via Editing IGFBP7 in Esophageal Squamous Cell Carcinoma. Int. J. Oncol. 50, 622-630. doi:10.3892/ ijo. 2016.3823

Chujo, T., and Suzuki, T. (2012). Trmt61B Is a Methyltransferase Responsible for 1-methyladenosine at Position 58 of Human Mitochondrial tRNAs. RNA 18, 2269-2276. doi:10.1261/rna.035600.112

Dai, X., Wang, T., Gonzalez, G., and Wang, Y. (2018). Identification of YTH Domain-Containing Proteins as the Readers for N1-Methyladenosine in RNA. Anal. Chem. 90, 6380-6384. doi:10.1021/acs.analchem.8b01703

Delaunay, S., and Frye, M. (2019). RNA Modifications Regulating Cell Fate in Cancer. Nat. Cel Biol 21, 552-559. doi:10.1038/s41556-019-0319-0

Deng, X., Jiang, Q., Liu, Z., and Chen, W. (2020). Clinical Significance of an m6A Reader Gene, IGF2BP2, in Head and Neck Squamous Cell Carcinoma. Front. Mol. Biosci. 7, 68. doi:10.3389/fmolb.2020.00068

Deng, Y., Li, K., Tan, F., and Liu, H. (2021). Gene Model Related to m6A Predicts the Prognostic Effect of Immune Infiltration on Head and Neck Squamous Cell Carcinoma. J. Oncol. 2021, 1814266. doi:10.1155/2021/1814266

Deutschmeyer, V. E., and Richter, A. M. (2020). The ZAR1 Protein in Cancer; from Epigenetic Silencing to Functional Characterisation and Epigenetic Therapy of Tumour Suppressors. Biochim. Biophys. Acta Rev. Cancer 1874, 188417. doi:10.1016/j.bbcan.2020.188417

Dimitrova, D. G., Teysset, L., and Carré, C. (2019). RNA 2'-O-Methylation (Nm) Modification in Human Diseases. Genes (Basel) 10, 117. doi:10.3390/ genes 10020117

Dominissini, D., Nachtergaele, S., Moshitch-Moshkovitz, S., Peer, E., Kol, N., BenHaim, M. S., et al. (2016). The Dynamic N(1)-methyladenosine Methylome in Eukaryotic Messenger RNA. Nature 530, 441-446. doi:10.1038/nature16998

Dong, X., Chen, G., Cai, Z., Li, Z., Qiu, L., Xu, H., et al. (2018). CDK13 RNA Overediting Mediated by ADAR1 Associates with Poor Prognosis of Hepatocellular Carcinoma Patients. Cell Physiol Biochem 47, 2602-2612. doi:10.1159/ 000491656

Duhen, R., Ballesteros-Merino, C., Frye, A. K., Tran, E., Rajamanickam, V., Chang, S. C., et al. (2021). Neoadjuvant Anti-OX40 (MEDI6469) Therapy in Patients with Head and Neck Squamous Cell Carcinoma Activates and Expands Antigen-specific Tumor-Infiltrating T Cells. Nat. Commun. 12, 1047. doi:10.1038/s41467-021-21383-1

Eckmann, C. R., Rammelt, C., and Wahle, E. (2011). Control of Poly(A) Tail Length. WIREs RNA 2, 348-361. doi:10.1002/wrna.56

Feng, Z. Y., Gao, H. Y., and Feng, T. D. (2021). Immune Infiltrates of m6A RNA Methylation-Related lncRNAs and Identification of PD-L1 in Patients with Primary Head and Neck Squamous Cell Carcinoma. Front Cel Dev Biol 9, 672248. doi:10.3389/fcell.2021.672248

Ferlay, J., Colombet, M., Soerjomataram, I., Mathers, C., Parkin, D. M., Piñeros, M., et al. (2019). Estimating the Global Cancer Incidence and Mortality in 2018: GLOBOCAN Sources and Methods. Int. J. Cancer 144, 1941-1953. doi:10.1002/ ijc.31937

Fu, L., Qin, Y. R., Ming, X. Y., Zuo, X. B., Diao, Y. W., Zhang, L. Y., et al. (2017). RNA Editing of SLC22A3 Drives Early Tumor Invasion and Metastasis in
Familial Esophageal Cancer. Proc. Natl. Acad. Sci. U S A. 114, E4631-E4640. doi:10.1073/pnas.1703178114

Fumagalli, D., Gacquer, D., Rothé, F., Lefort, A., Libert, F., Brown, D., et al. (2015). Principles Governing A-To-I RNA Editing in the Breast Cancer Transcriptome. Cell Rep 13, 277-289. doi:10.1016/j.celrep.2015.09.032

Geng, X., Zhang, Y., Zeng, Z., Zhu, Z., Wang, H., Yu, W., et al. (2021). Molecular Characteristics, Prognostic Value, and Immune Characteristics of m6A Regulators Identified in Head and Neck Squamous Cell Carcinoma. Front. Oncol. 11, 629718. doi:10.3389/fonc.2021.629718

Gong, J., Chehrazi-Raffle, A., Reddi, S., and Salgia, R. (2018). Development of PD-1 and PD-L1 Inhibitors as a Form of Cancer Immunotherapy: a Comprehensive Review of Registration Trials and Future Considerations. J. Immunother. Cancer 6, 8. doi:10.1186/s40425-018-0316-z

Grassi, E., Santoro, R., Umbach, A., Grosso, A., Oliviero, S., Neri, F., et al. (2018). Choice of Alternative Polyadenylation Sites, Mediated by the RNA-Binding Protein Elavl3, Plays a Role in Differentiation of Inhibitory Neuronal Progenitors. Front Cel Neurosci 12, 518. doi:10.3389/fncel.2018.00518

Gruber, A. J., and Zavolan, M. (2019). Alternative Cleavage and Polyadenylation in Health and Disease. Nat. Rev. Genet. 20, 599-614. doi:10.1038/s41576-0190145-z

Han, J., An, O., Hong, H., Chan, T. H. M., Song, Y., Shen, H., et al. (2020). Suppression of Adenosine-To-Inosine (A-To-I) RNA Editome by Death Associated Protein 3 (DAP3) Promotes Cancer Progression. Sci. Adv. 6, eaba5136. doi:10.1126/sciadv.aba5136

Han, J., Wang, J. Z., Yang, X., Yu, H., Zhou, R., Lu, H. C., et al. (2019). METTL3 Promote Tumor Proliferation of Bladder Cancer by Accelerating Pri-miR221/ 222 Maturation in m6A-dependent Manner. Mol. Cancer 18, 110. doi:10.1186/ s12943-019-1036-9

Han, L., Diao, L., Yu, S., Xu, X., Li, J., Zhang, R., et al. (2015). The Genomic Landscape and Clinical Relevance of A-To-I RNA Editing in Human Cancers. Cancer Cell 28, 515-528. doi:10.1016/j.ccell.2015.08.013

He, X., Li, W., Liang, X., Zhu, X., Zhang, L., Huang, Y., et al. (2018). IGF2BP2 Overexpression Indicates Poor Survival in Patients with Acute Myelocytic Leukemia. Cel Physiol Biochem 51, 1945-1956. doi:10.1159/000495719

Heraud-Farlow, J. E., Chalk, A. M., and Walkley, C. R. (2019). Defining the Functions of Adenosine-To-Inosine RNA Editing through Hematology. Curr. Opin. Hematol. 26, 241-248. doi:10.1097/MOH.0000000000000514

Hochberg, M., Gilead, L., Markel, G., Nemlich, Y., Feiler, Y., Enk, C. D., et al. (2013). Insulin-like Growth Factor-Binding Protein-7 (IGFBP7) Transcript: A-To-I Editing Events in normal and Cancerous Human Keratinocytes. Arch. Dermatol. Res. 305, 519-528. doi:10.1007/s00403-013-1338-5

Hong, H., An, O., Chan, T. H. M., Ng, V. H. E., Kwok, H. S., Lin, J. S., et al. (2018). Bidirectional Regulation of Adenosine-To-Inosine (A-To-I) RNA Editing by DEAH Box Helicase 9 (DHX9) in Cancer. Nucleic Acids Res. 46, 7953-7969. doi:10.1093/nar/gky396

Hosaka, T., Yamashita, T., Teramoto, S., Hirose, N., Tamaoka, A., and Kwak, S. (2019). ADAR2-dependent A-To-I RNA Editing in the Extracellular Linear and Circular RNAs. Neurosci. Res. 147, 48-57. doi:10.1016/j.neures.2018.11.005

Huang, G. Z., Wu, Q. Q., Zheng, Z. N., Shao, T. R., Chen, Y. C., Zeng, W. S., et al. (2020). M6A-related Bioinformatics Analysis Reveals that HNRNPC Facilitates Progression of OSCC via EMT. Aging (Albany NY) 12, 11667-11684. doi:10.18632/aging.103333

Ichinose, J., Watanabe, K., Sano, A., Nagase, T., Nakajima, J., Fukayama, M., et al. (2014). Alternative Polyadenylation Is Associated with Lower Expression of PABPN1 and Poor Prognosis in Non-small Cell Lung Cancer. Cancer Sci. 105, 1135-1141. doi:10.1111/cas.12472

Ikeda, T., Saito-Takatsuji, H., Yoshitomi, Y., and Yonekura, H. (2020). Role of Arginine Methylation in Alternative Polyadenylation of VEGFR-1 (Flt-1) PremRNA. Int. J. Mol. Sci. 21, 6460. doi:10.3390/ijms21186460

Ji, Z., and Tian, B. (2009). Reprogramming of 3' Untranslated Regions of mRNAs by Alternative Polyadenylation in Generation of Pluripotent Stem Cells from Different Cell Types. PLoS One 4, e8419. doi:10.1371/journal.pone.0008419

Jia, G., Fu, Y., Zhao, X., Dai, Q., Zheng, G., Yang, Y., et al. (2011). N6methyladenosine in Nuclear RNA Is a Major Substrate of the ObesityAssociated FTO. Nat. Chem. Biol. 7, 885-887. doi:10.1038/nchembio.687

Johnson, D. E., Burtness, B., Leemans, C. R., Lui, V. W. Y., Bauman, J. E., and Grandis, J. R. (2020). Head and Neck Squamous Cell Carcinoma. Nat. Rev. Dis. Primers 6, 92. doi:10.1038/s41572-020-00224-3 
Kawarada, L., Suzuki, T., Ohira, T., Hirata, S., Miyauchi, K., and Suzuki, T. (2017). ALKBH1 Is an RNA Dioxygenase Responsible for Cytoplasmic and Mitochondrial tRNA Modifications. Nucleic Acids Res. 45, 7401-7415. doi:10.1093/nar/gkx354

Kretschmer, J., Rao, H., Hackert, P., Sloan, K. E., Höbartner, C., and Bohnsack, M. T. (2018). The m6A Reader Protein YTHDC2 Interacts with the Small Ribosomal Subunit and the 5'-3' Exoribonuclease XRN1. RNA 24, 1339-1350. doi:10.1261/rna.064238.117

Kühn, U., Gündel, M., Knoth, A., Kerwitz, Y., Rüdel, S., and Wahle, E. (2009). Poly(A) Tail Length Is Controlled by the Nuclear Poly(A)-binding Protein Regulating the Interaction between Poly(A) Polymerase and the Cleavage and Polyadenylation Specificity Factor. J. Biol. Chem. 284, 22803-22814. doi:10.1074/jbc.M109.018226

Lee, J. T. (2012). Epigenetic Regulation by Long Noncoding RNAs. Science 338, 1435-1439. doi:10.1126/science.1231776

Lee, Y. G., Chang, H., Keam, B., Chun, S. H., Park, J., Park, K. U., et al. (2021). Outcomes and Biomarkers of Immune Checkpoint Inhibitor Therapy in Patients with Refractory Head and Neck Squamous Cell Carcinoma: KCSG HN18-12. Cancer Res. Treat. 53, 671-677. doi:10.4143/crt.2020.824

Lehmann, K. A., and Bass, B. L. (2000). Double-stranded RNA Adenosine Deaminases ADAR1 and ADAR2 Have Overlapping Specificities. Biochemistry 39, 12875-12884. doi:10.1021/bi001383g

León, X., Hitt, R., Constenla, M., Rocca, A., Stupp, R., Kovács, A. F., et al. (2005). A Retrospective Analysis of the Outcome of Patients with Recurrent And/or Metastatic Squamous Cell Carcinoma of the Head and Neck Refractory to a Platinum-Based Chemotherapy. Clin. Oncol. (R Coll. Radiol. 17, 418-424. doi:10.1016/j.clon.2005.02.014

Li, F., Yi, Y., Miao, Y., Long, W., Long, T., Chen, S., et al. (2019a). N6-Methyladenosine Modulates Nonsense-Mediated mRNA Decay in Human Glioblastoma. Cancer Res. 79, 5785-5798. doi:10.1158/0008-5472.CAN-18-2868

Li, J., Zhang, C., Yuan, X., and Cao, Y. (2021). Molecular Characteristics of N1Methyladenosine Regulators and Their Correlation with Overall Cancer Survival. DNA Cel Biol 40, 513-522. doi:10.1089/dna.2020.6214

Li, T., Hu, P. S., Zuo, Z., Lin, J. F., Li, X., Wu, Q. N., et al. (2019b). METTL3 Facilitates Tumor Progression via an m6A-igf2bp2-dependent Mechanism in Colorectal Carcinoma. Mol. Cancer 18, 112. doi:10.1186/s12943-019-1038-7

Li, X., Xiong, X., Wang, K., Wang, L., Shu, X., Ma, S., et al. (2016). Transcriptomewide Mapping Reveals Reversible and Dynamic N(1)-methyladenosine Methylome. Nat. Chem. Biol. 12, 311-316. doi:10.1038/nchembio.2040

Li, X., Xiong, X., Zhang, M., Wang, K., Chen, Y., Zhou, J., et al. (2017). BaseResolution Mapping Reveals Distinct m1A Methylome in Nuclear- and Mitochondrial-Encoded Transcripts. Mol. Cel 68, 993-e9. doi:10.1016/ j.molcel.2017.10.019

Li, Y., Zheng, J. N., Wang, E. H., Gong, C. J., Lan, K. F., and Ding, X. (2020a). The m6A Reader Protein YTHDC2 Is a Potential Biomarker and Associated with Immune Infiltration in Head and Neck Squamous Cell Carcinoma. PeerJ 8, e10385. doi:10.7717/peerj.10385

Li, Y. Q., Chen, Y., Xu, Y. F., He, Q. M., Yang, X. J., Li, Y. Q., et al. (2020b). FNDC3B 3'-UTR Shortening Escapes from microRNA-Mediated Gene Repression and Promotes Nasopharyngeal Carcinoma Progression. Cancer Sci. 111, 1991-2003. doi:10.1111/cas.14394

Li, Z., Zhao, P., and Xia, Q. (2019c). Epigenetic Methylations on N6-Adenine and N6-Adenosine with the Same Input but Different Output. Int. J. Mol. Sci. 20, 2931. doi:10.3390/ijms20122931

Lin, Y., Li, Z., Ozsolak, F., Kim, S. W., Arango-Argoty, G., Liu, T. T., et al. (2012). An In-Depth Map of Polyadenylation Sites in Cancer. Nucleic Acids Res. 40, 8460-8471. doi:10.1093/nar/gks637

Liu, F., Clark, W., Luo, G., Wang, X., Fu, Y., Wei, J., et al. (2016). ALKBH1Mediated tRNA Demethylation Regulates Translation. Cell 167, 816-e16. doi:10.1016/j.cell.2016.09.038

Liu, L., Wu, Y., Li, Q., Liang, J., He, Q., Zhao, L., et al. (2020). METTL3 Promotes Tumorigenesis and Metastasis through BMI1 m6A Methylation in Oral Squamous Cell Carcinoma. Mol. Ther. 28, 2177-2190. doi:10.1016/ j.ymthe.2020.06.024

Liu, X., Fu, Y., Huang, J., Wu, M., Zhang, Z., Xu, R., et al. (2019). ADAR1 Promotes the Epithelial-To-Mesenchymal Transition and Stem-like Cell Phenotype of Oral Cancer by Facilitating Oncogenic microRNA Maturation. J. Exp. Clin. Cancer Res. 38, 315. doi:10.1186/s13046-019-1300-2
Liu, Z., Williams, M., Stewart, J., Glisson, B. S., Fuller, C., and Roy-Chowdhuri, S. (2021). Evaluation of Programmed Death Ligand 1 Expression in Cytology to Determine Eligibility for Immune Checkpoint Inhibitor Therapy in Patients with Head and Neck Squamous Cell Carcinoma. Cancer Cytopathol. doi:10.1002/cncy.22501

Ma, W., Chen, C., Liu, Y., Zeng, M., Meyers, B. C., Li, J., et al. (2018). Coupling of microRNA-Directed Phased Small Interfering RNA Generation from Long Noncoding Genes with Alternative Splicing and Alternative Polyadenylation in Small RNA-Mediated Gene Silencing. New Phytol. 217, 1535-1550. doi:10.1111/nph.14934

Ma, Y., Han, J., and Luo, X. (2021). FOXD1-AS1 Upregulates FOXD1 to Promote Oral Squamous Cell Carcinoma Progression. Oral Dis. doi:10.1111/odi.14002

Macdonald, C. C. (2019). Tissue-specific Mechanisms of Alternative Polyadenylation: Testis, Brain, and beyond (2018 Update). Wiley Interdiscip. Rev. RNA 10, e1526. doi:10.1002/wrna.1526

Mao, L., Xiao, Y., Yang, Q. C., Yang, S. C., Yang, L. L., and Sun, Z. J. (2021). TIGIT/ CD155 Blockade Enhances Anti-PD-L1 Therapy in Head and Neck Squamous Cell Carcinoma by Targeting Myeloid-Derived Suppressor Cells. Oral Oncol. 121, 105472. doi:10.1016/j.oraloncology.2021.105472

Martin, G., Gruber, A. R., Keller, W., and Zavolan, M. (2012). Genome-wide Analysis of Pre-mRNA 3' End Processing Reveals a Decisive Role of Human Cleavage Factor I in the Regulation of 3' UTR Length. Cel Rep 1, 753-763. doi:10.1016/j.celrep.2012.05.003

Meng, Q. Z., Cong, C. H., Li, X. J., Zhu, F., Zhao, X., and Chen, F. W. (2020). METTL3 Promotes the Progression of Nasopharyngeal Carcinoma through Mediating M6A Modification of EZH2. Eur. Rev. Med. Pharmacol. Sci. 24, 4328-4336. doi:10.26355/eurrev_202004_21014

Meyer, K., Köster, T., Nolte, C., Weinholdt, C., Lewinski, M., Grosse, I., et al. (2017). Adaptation of iCLIP to Plants Determines the Binding Landscape of the Clock-Regulated RNA-Binding Protein AtGRP7. Genome Biol. 18, 204. doi:10.1186/s13059-017-1332-x

Missan, D. S., Mitchell, K., Subbaram, S., and Dipersio, C. M. (2015). Integrin a $3 \beta 1$ Signaling through MEK/ERK Determines Alternative Polyadenylation of the MMP-9 mRNA Transcript in Immortalized Mouse Keratinocytes. PLoS One 10, e0119539. doi:10.1371/journal.pone.0119539

Murthy, K. G., and Manley, J. L. (1995). The 160-kD Subunit of Human CleavagePolyadenylation Specificity Factor Coordinates Pre-mRNA 3'-end Formation. Genes Dev. 9, 2672-2683. doi:10.1101/gad.9.21.2672

Nagano, T., and Fraser, P. (2011). No-nonsense Functions for Long Noncoding RNAs. Cell 145, 178-181. doi:10.1016/j.cell.2011.03.014

Nishikura, K. (2010). Functions and Regulation of RNA Editing by ADAR Deaminases. Annu. Rev. Biochem. 79, 321-349. doi:10.1146/annurevbiochem-060208-105251

Oakes, E., Anderson, A., Cohen-Gadol, A., and Hundley, H. A. (2017). Adenosine Deaminase that Acts on RNA 3 (ADAR3) Binding to Glutamate Receptor Subunit B Pre-mRNA Inhibits RNA Editing in Glioblastoma. J. Biol. Chem. 292, 4326-4335. doi:10.1074/jbc.M117.779868

Ozanick, S., Krecic, A., Andersland, J., and Anderson, J. T. (2005). The Bipartite Structure of the tRNA m1A58 Methyltransferase from S. cerevisiae Is Conserved in Humans. RNA 11, 1281-1290. doi:10.1261/rna.5040605

Pan, J., Huang, Z., and Xu, Y. (2021). m5C RNA Methylation Regulators Predict Prognosis and Regulate the Immune Microenvironment in Lung Squamous Cell Carcinoma. Front. Oncol. 11, 657466. doi:10.3389/fonc.2021.657466

Pan, Q., Shai, O., Lee, L. J., Frey, B. J., and Blencowe, B. J. (2008). Deep Surveying of Alternative Splicing Complexity in the Human Transcriptome by HighThroughput Sequencing. Nat. Genet. 40, 1413-1415. doi:10.1038/ng.259

Paramasivam, A., George, R., and Priyadharsini, J. V. (2021). Genomic and Transcriptomic Alterations in m6A Regulatory Genes Are Associated with Tumorigenesis and Poor Prognosis in Head and Neck Squamous Cell Carcinoma. Am. J. Cancer Res. 11, 3688-3697.

Passacantilli, I., Panzeri, V., Bielli, P., Farini, D., Pilozzi, E., Fave, G. D., et al. (2017). Alternative Polyadenylation of ZEB1 Promotes its Translation during Genotoxic Stress in Pancreatic Cancer Cells. Cell Death Dis 8, e3168. doi:10.1038/cddis.2017.562

Patterson, J. B., and Samuel, C. E. (1995). Expression and Regulation by Interferon of a Double-stranded-RNA-specific Adenosine Deaminase from Human Cells: Evidence for Two Forms of the Deaminase. Mol. Cel Biol 15, 5376-5388. doi:10.1128/mcb.15.10.5376 
Paz-Yaacov, N., Bazak, L., Buchumenski, I., Porath, H. T., Danan-Gotthold, M., Knisbacher, B. A., et al. (2015). Elevated RNA Editing Activity Is a Major Contributor to Transcriptomic Diversity in Tumors. Cel Rep 13, 267-276. doi:10.1016/j.celrep.2015.08.080

Ponting, C. P., and Belgard, T. G. (2010). Transcribed Dark Matter: Meaning or Myth? Hum. Mol. Genet. 19, R162-R168. doi:10.1093/hmg/ddq362

Qiao, J. J., Chan, T. H., Qin, Y. R., and Chen, L. (2014). ADAR1: a Promising New Biomarker for Esophageal Squamous Cell Carcinoma? Expert Rev. Anticancer Ther. 14, 865-868. doi:10.1586/14737140.2014.928595

Qin, Y. R., Qiao, J. J., Chan, T. H., Zhu, Y. H., Li, F. F., Liu, H., et al. (2014). Adenosine-to-inosine RNA Editing Mediated by ADARs in Esophageal Squamous Cell Carcinoma. Cancer Res. 74, 840-851. doi:10.1158/00085472.CAN-13-2545

Rajasekar, V., Geo, V. E., Martin, L. J., and Nagalingam, B. (2020). The Combined Effect of Low Viscous Biofuel and EGR on NO-Smoke Tradeoff in a Biodiesel Engine-An Experimental Study. Environ. Sci. Pollut. Res. Int. 27, 17468-17480. doi:10.1007/s11356-019-05449-8

Ramanathan, A., Robb, G. B., and Chan, S. H. (2016). mRNA Capping: Biological Functions and Applications. Nucleic Acids Res. 44, 7511-7526. doi:10.1093/nar/ gkw551

Roth, S. H., Levanon, E. Y., and Eisenberg, E. (2019). Genome-wide Quantification of ADAR Adenosine-To-Inosine RNA Editing Activity. Nat. Methods 16, 1131-1138. doi:10.1038/s41592-019-0610-9

Safra, M., Sas-Chen, A., Nir, R., Winkler, R., Nachshon, A., Bar-Yaacov, D., et al. (2017). The m1A Landscape on Cytosolic and Mitochondrial mRNA at SingleBase Resolution. Nature 551, 251-255. doi:10.1038/nature24456

Sakai, A., Ando, M., Fukusumi, T., Ren, S., Liu, C., Qualliotine, J., et al. (2020). Aberrant Expression of CPSF1 Promotes Head and Neck Squamous Cell Carcinoma via Regulating Alternative Splicing. PLoS One 15, e0233380. doi:10.1371/journal.pone. 0233380

Sandberg, R., Neilson, J. R., Sarma, A., Sharp, P. A., and Burge, C. B. (2008). Proliferating Cells Express mRNAs with Shortened 3' Untranslated Regions and Fewer microRNA Target Sites. Science 320, 1643-1647. doi:10.1126/ science. 1155390

Shi, H., Wei, J., and He, C. (2019). Where, when, and How: Context-dependent Functions of RNA Methylation Writers, Readers, and Erasers. Mol. Cel 74, 640-650. doi:10.1016/j.molcel.2019.04.025

Shi, L., Chen, W., Zhang, Z., Chen, J., and Xue, M. (2021). N1-methyladenosine Profiling of Long Non-coding RNA in Colorectal Cancer. IUBMB Life 73, 1235. doi:10.1002/iub.2534

Shi, Q., Xue, C., Yuan, X., He, Y., and Yu, Z. (2020). Gene Signatures and Prognostic Values of m1A-Related Regulatory Genes in Hepatocellular Carcinoma. Sci. Rep. 10, 15083. doi:10.1038/s41598-020-72178-1

Shi, X., Sun, M., Liu, H., Yao, Y., and Song, Y. (2013). Long Non-coding RNAs: a New Frontier in the Study of Human Diseases. Cancer Lett. 339, 159-166. doi:10.1016/j.canlet.2013.06.013

Shriwas, O., Priyadarshini, M., Samal, S. K., Rath, R., Panda, S., Das Majumdar, S. K., et al. (2020). DDX3 Modulates Cisplatin Resistance in OSCC through ALKBH5-Mediated m6A-Demethylation of FOXM1 and NANOG. Apoptosis 25, 233-246. doi:10.1007/s10495-020-01591-8

Simpson, L., and Emeson, R. B. (1996). RNA Editing. Annu. Rev. Neurosci. 19, 27-52. doi:10.1146/annurev.ne.19.030196.000331

Sobol, R. E., Menander, K. B., Chada, S., Wiederhold, D., Sellman, B., Talbott, M., et al. (2021). Analysis of Adenoviral P53 Gene Therapy Clinical Trials in Recurrent Head and Neck Squamous Cell Carcinoma. Front. Oncol. 11, 645745. doi:10.3389/fonc.2021.645745

Stewart, J. S., Cohen, E. E., Licitra, L., Van Herpen, C. M., Khorprasert, C., Soulieres, D., et al. (2009). Phase III Study of Gefitinib Compared with Intravenous Methotrexate for Recurrent Squamous Cell Carcinoma of the Head and Neck [corrected]. J. Clin. Oncol. 27, 1864-1871. doi:10.1200/ JCO.2008.17.0530

Sun, M., Ding, J., Li, D., Yang, G., Cheng, Z., and Zhu, Q. (2017). NUDT21 Regulates 3'-UTR Length and microRNA-Mediated Gene Silencing in Hepatocellular Carcinoma. Cancer Lett. 410, 158-168. doi:10.1016/ j.canlet.2017.09.026

Sun, M., Ju, H., Zhou, Z., and Zhu, R. (2014). Pilot Genome-wide Study of Tandem 3' UTRs in Esophageal Cancer Using High-Throughput Sequencing. Mol. Med. Rep. 9, 1597-1605. doi:10.3892/mmr.2014.2003
Sung, H., Ferlay, J., Siegel, R. L., Laversanne, M., Soerjomataram, I., Jemal, A., et al. (2021). Global Cancer Statistics 2020: GLOBOCAN Estimates of Incidence and Mortality Worldwide for 36 Cancers in 185 Countries. CA Cancer J. Clin. 71, 209-249. doi:10.3322/caac.21660

Takahashi, M., Yoshimoto, T., Shimoda, M., Kono, T., Koizumi, M., Yazumi, S., et al. (2006). Loss of Function of the Candidate Tumor Suppressor Proxl by RNA Mutation in Human Cancer Cells. Neoplasia 8, 1003-1010. doi:10.1593/ neo.06595

Tan, S., Li, H., Zhang, W., Shao, Y., Liu, Y., Guan, H., et al. (2018). NUDT21 Negatively Regulates PSMB2 and CXXC5 by Alternative Polyadenylation and Contributes to Hepatocellular Carcinoma Suppression. Oncogene 37, 4887-4900. doi:10.1038/s41388-018-0280-6

Terajima, H., Yoshitane, H., Yoshikawa, T., Shigeyoshi, Y., and Fukada, Y. (2018). A-to-I RNA Editing Enzyme ADAR2 Regulates Light-Induced Circadian Phase-Shift. Sci. Rep. 8, 14848. doi:10.1038/s41598-018-33114-6

Tian, B., and Manley, J. L. (2017). Alternative Polyadenylation of mRNA Precursors. Nat. Rev. Mol. Cel Biol 18, 18-30. doi:10.1038/nrm.2016.116

Ueda, Y., Ooshio, I., Fusamae, Y., Kitae, K., Kawaguchi, M., Jingushi, K., et al. (2017). AlkB Homolog 3-mediated tRNA Demethylation Promotes Protein Synthesis in Cancer Cells. Sci. Rep. 7, 42271. doi:10.1038/srep42271

Valente, L., and Nishikura, K. (2005). ADAR Gene Family and A-To-I RNA Editing: Diverse Roles in Posttranscriptional Gene Regulation. Prog. Nucleic Acid Res. Mol. Biol. 79, 299-338. doi:10.1016/S0079-6603(04)79006-6

Vermorken, J. B., Mesia, R., Rivera, F., Remenar, E., Kawecki, A., Rottey, S., et al. (2008). Platinum-based Chemotherapy Plus Cetuximab in Head and Neck Cancer. N. Engl. J. Med. 359, 1116-1127. doi:10.1056/NEJMoa0802656

Vermorken, J. B., Psyrri, A., Mesía, R., Peyrade, F., Beier, F., De Blas, B., et al. (2014). Impact of Tumor HPV Status on Outcome in Patients with Recurrent And/or Metastatic Squamous Cell Carcinoma of the Head and Neck Receiving Chemotherapy with or without Cetuximab: Retrospective Analysis of the Phase III EXTREME Trial. Ann. Oncol. 25, 801-807. doi:10.1093/annonc/mdt574

Vilardo, E., Nachbagauer, C., Buzet, A., Taschner, A., Holzmann, J., and Rossmanith, W. (2012). A Subcomplex of Human Mitochondrial RNase P Is a Bifunctional Methyltransferase-Eextensive Moonlighting in Mitochondrial tRNA Biogenesis. Nucleic Acids Res. 40, 11583-11593. doi:10.1093/nar/gks910

Vlachogiannis, N. I., Sachse, M., Georgiopoulos, G., Zormpas, E., Bampatsias, D., Delialis, D., et al. (2021). Adenosine-to-inosine Alu RNA Editing Controls the Stability of the Pro-inflammatory Long Noncoding RNA NEAT1 in Atherosclerotic Cardiovascular Disease. J. Mol. Cel Cardiol 160, 111-120. doi:10.1016/j.yjmcc.2021.07.005

Wahle, E. (1995). Poly(A) Tail Length Control Is Caused by Termination of Processive Synthesis. J. Biol. Chem. 270, 2800-2808. doi:10.1074/jbc.270.6.2800

Wang, C. S., Chang, C. H., Tzeng, T. Y., Lin, A. M., and Lo, Y. L. (2021a). Geneediting by CRISPR-Cas9 in Combination with Anthracycline Therapy via Tumor Microenvironment-Switchable, EGFR-Targeted, and NucleusDirected Nanoparticles for Head and Neck Cancer Suppression. Nanoscale Horiz 6, 729-743. doi:10.1039/d1nh00254f

Wang, E. T., Sandberg, R., Luo, S., Khrebtukova, I., Zhang, L., Mayr, C., et al. (2008). Alternative Isoform Regulation in Human Tissue Transcriptomes. Nature 456, 470-476. doi:10.1038/nature07509

Wang, K., Jiang, L., Zhang, Y., and Chen, C. (2020a). Progression of Thyroid Carcinoma Is Promoted by the m6A Methyltransferase METTL3 through Regulating m6A Methylation on TCF1. Onco Targets Ther. 13, 1605-1612. doi:10.2147/OTT.S234751

Wang, L., Lang, G. T., Xue, M. Z., Yang, L., Chen, L., Yao, L., et al. (2020b). Dissecting the Heterogeneity of the Alternative Polyadenylation Profiles in Triple-Negative Breast Cancers. Theranostics 10, 10531-10547. doi:10.7150/ thno.40944

Wang, Q., Zhang, Q., Huang, Y., and Zhang, J. (2020c). m1A Regulator TRMT10C Predicts Poorer Survival and Contributes to Malignant Behavior in Gynecological Cancers. DNA Cel Biol 39, 1767-1778. doi:10.1089/ dna.2020.5624

Wang, W., Xiong, Y., Ding, X., Wang, L., Zhao, Y., Fei, Y., et al. (2019a). Cathepsin L Activated by Mutant P53 and Egr-1 Promotes Ionizing Radiation-Induced EMT in Human NSCLC. J. Exp. Clin. Cancer Res. 38, 61. doi:10.1186/s13046019-1054-x

Wang, X., Fu, X., Zhang, J., Xiong, C., Zhang, S., and Lv, Y. (2020d). Identification and Validation of m6A RNA Methylation Regulators with Clinical Prognostic 
Value in Papillary Thyroid Cancer. Cancer Cel Int 20, 203. doi:10.1186/s12935020-01283-y

Wang, X., Tian, L., Li, Y., Wang, J., Yan, B., Yang, L., et al. (2021b). RBM15 Facilitates Laryngeal Squamous Cell Carcinoma Progression by Regulating TMBIM6 Stability through IGF2BP3 Dependent. J. Exp. Clin. Cancer Res. 40, 80. doi:10.1186/s13046-021-01871-4

Wang, Y., Chung, D. H., Monteleone, L. R., Li, J., Chiang, Y., Toney, M. D., et al. (2019b). RNA Binding Candidates for Human ADAR3 from Substrates of a Gain of Function Mutant Expressed in Neuronal Cells. Nucleic Acids Res. 47, 10801-10814. doi:10.1093/nar/gkz815

Wong, S. K., Sato, S., and Lazinski, D. W. (2001). Substrate Recognition by ADAR1 and ADAR2. RNA 7, 846-858. doi:10.1017/s135583820101007x

Wu, P., Fang, X., Liu, Y., Tang, Y., Wang, W., Li, X., et al. (2021). N6methyladenosine Modification of circCUX1 Confers Radioresistance of Hypopharyngeal Squamous Cell Carcinoma through Caspasel Pathway. Cel Death Dis 12, 298. doi:10.1038/s41419-021-03558-2

Wu, T. P., Wang, T., Seetin, M. G., Lai, Y., Zhu, S., Lin, K., et al. (2016). DNA Methylation on N(6)-adenine in Mammalian Embryonic Stem Cells. Nature 532, 329-333. doi:10.1038/nature17640

Xia, T., Wu, X., Cao, M., Zhang, P., Shi, G., Zhang, J., et al. (2019). The RNA m6A Methyltransferase METTL3 Promotes Pancreatic Cancer Cell Proliferation and Invasion. Pathol. Res. Pract. 215, 152666. doi:10.1016/j.prp.2019.152666

Xia, T. L., Li, X., Wang, X., Zhu, Y. J., Zhang, H., Cheng, W., et al. (2021). N(6)methyladenosine-binding Protein YTHDF1 Suppresses EBV Replication and Promotes EBV RNA Decay. EMBO Rep. 22, e50128. doi:10.15252/ embr.202050128

Xia, Z., Donehower, L. A., Cooper, T. A., Neilson, J. R., Wheeler, D. A., Wagner, E. J., et al. (2014). Dynamic Analyses of Alternative Polyadenylation from RNASeq Reveal a 3'-UTR Landscape across Seven Tumour Types. Nat. Commun. 5, 5274. doi:10.1038/ncomms6274

Xiang, Y., Ye, Y., Lou, Y., Yang, Y., Cai, C., Zhang, Z., et al. (2018). Comprehensive Characterization of Alternative Polyadenylation in Human Cancer. J. Natl. Cancer Inst. 110, 379-389. doi:10.1093/jnci/djx223

Xie, S., Chen, W., Chen, K., Chang, Y., Yang, F., Lin, A., et al. (2020). Emerging Roles of RNA Methylation in Gastrointestinal Cancers. Cancer Cel Int 20, 585. doi:10.1186/s12935-020-01679-w

Xiong, M., Chen, L., Zhou, L., Ding, Y., Kazobinka, G., Chen, Z., et al. (2019). NUDT21 Inhibits Bladder Cancer Progression through ANXA2 and LIMK2 by Alternative Polyadenylation. Theranostics 9, 7156-7167. doi:10.7150/ thno. 36030

Xu, L., Liu, X., Sheng, N., Oo, K. S., Liang, J., Chionh, Y. H., et al. (2017). Three Distinct 3-methylcytidine (m3C) Methyltransferases Modify tRNA and mRNA in Mice and Humans. J. Biol. Chem. 292, 14695-14703. doi:10.1074/ jbc.M117.798298

Xu, X., Wang, Y., Mojumdar, K., Zhou, Z., Jeong, K. J., Mangala, L. S., et al. (2019a). A-to-I-edited miRNA-379-5p Inhibits Cancer Cell Proliferation through CD97Induced Apoptosis. J. Clin. Invest. 129, 5343-5356. doi:10.1172/JCI123396

Xu, X., Yu, Y., Zong, K., Lv, P., and Gu, Y. (2019b). Up-regulation of IGF2BP2 by Multiple Mechanisms in Pancreatic Cancer Promotes Cancer Proliferation by Activating the PI3K/Akt Signaling Pathway. J. Exp. Clin. Cancer Res. 38, 497. doi:10.1186/s13046-019-1470-y

Xu, Y. F., Li, Y. Q., Liu, N., He, Q. M., Tang, X. R., Wen, X., et al. (2018). Differential Genome-wide Profiling of Alternative Polyadenylation Sites in Nasopharyngeal Carcinoma by High-Throughput Sequencing. J. Biomed. Sci. 25, 74. doi:10.1186/s12929-018-0477-6

Yao, L., Wang, H., Song, Y., Dai, Z., Yu, H., Yin, M., et al. (2019). Large-scale Prediction of ADAR-Mediated Effective Human A-To-I RNA Editing. Brief Bioinform 20, 102-109. doi:10.1093/bib/bbx092

Ye, J., Wang, Z., Chen, X., Jiang, X., Dong, Z., Hu, S., et al. (2020). YTHDF1enhanced Iron Metabolism Depends on TFRC m6A Methylation. Theranostics 10, 12072-12089. doi:10.7150/thno.51231

Yi, L., Wu, G., Guo, L., Zou, X., and Huang, P. (2020). Comprehensive Analysis of the PD-L1 and Immune Infiltrates of m6A RNA Methylation Regulators in Head and Neck Squamous Cell Carcinoma. Mol. Ther. Nucleic Acids 21, 299-314. doi:10.1016/j.omtn.2020.06.001

Yoshimoto, T., Takahashi, M., Nagayama, S., Watanabe, G., Shimada, Y., Sakasi, Y., et al. (2007). RNA Mutations of Prox1 Detected in Human Esophageal Cancer
Cells by the Shifted Termination Assay. Biochem. Biophys. Res. Commun. 359, 258-262. doi:10.1016/j.bbrc.2007.05.071

Yu, J., Zhang, C., Yu, Q., Yu, H., and Zhang, B. (2019). ADAR1 P110 Enhances Adhesion of Tumor Cells to Extracellular Matrix in Hepatocellular Carcinoma via Up-Regulating ITGA2 Expression. Med. Sci. Monit. 25, 1469-1479. doi:10.12659/MSM.911944

Yu, X., Harden, K., Gonzalez, L. C., Francesco, M., Chiang, E., Irving, B., et al. (2009). The Surface Protein TIGIT Suppresses T Cell Activation by Promoting the Generation of Mature Immunoregulatory Dendritic Cells. Nat. Immunol. 10, 48-57. doi:10.1038/ni.1674

Yue, B., Song, C., Yang, L., Cui, R., Cheng, X., Zhang, Z., et al. (2019). METTL3mediated N6-Methyladenosine Modification Is Critical for EpithelialMesenchymal Transition and Metastasis of Gastric Cancer. Mol. Cancer 18 , 142. doi:10.1186/s12943-019-1065-4

Zhang, J., Chen, Z., Tang, Z., Huang, J., Hu, X., and He, J. (2017). RNA Editing Is Induced by Type I Interferon in Esophageal Squamous Cell Carcinoma. Tumour Biol. 39, 1010428317708546. doi:10.1177/1010428317708546

Zhang, L., Yang, C. S., Varelas, X., and Monti, S. (2016). Altered RNA Editing in 3' UTR Perturbs microRNA-Mediated Regulation of Oncogenes and TumorSuppressors. Sci. Rep. 6, 23226. doi:10.1038/srep23226

Zhang, Y., Wang, K., Zhao, Z., Sun, S., Zhang, K., Huang, R., et al. (2018). ADAR3 Expression Is an Independent Prognostic Factor in Lower-Grade Diffuse Gliomas and Positively Correlated with the Editing Level of GRIA2Q607R. Cancer Cel Int 18, 196. doi:10.1186/s12935-018-0695-8

Zhao, X., and Cui, L. (2019). Development and Validation of a m6A RNA Methylation Regulators-Based Signature for Predicting the Prognosis of Head and Neck Squamous Cell Carcinoma. Am. J. Cancer Res. 9, 2156-2169.

Zhao, Y., Zhao, Q., Kaboli, P. J., Shen, J., Li, M., Wu, X., et al. (2019). m1A Regulated Genes Modulate PI3K/AKT/mTOR and ErbB Pathways in Gastrointestinal Cancer. Transl Oncol. 12, 1323-1333. doi:10.1016/ j.tranon.2019.06.007

Zheng, D., and Tian, B. (2014). RNA-binding Proteins in Regulation of Alternative Cleavage and Polyadenylation. Adv. Exp. Med. Biol. 825, 97-127. doi:10.1007/ 978-1-4939-1221-6_3

Zheng, Q., Yu, X., Zhang, Q., He, Y., and Guo, W. (2021). Genetic Characteristics and Prognostic Implications of m1A Regulators in Pancreatic Cancer. Biosci. Rep. 41, 337. doi:10.1042/bsr20210337

Zhou, X., Han, J., Zhen, X., Liu, Y., Cui, Z., Yue, Z., et al. (2020). Analysis of Genetic Alteration Signatures and Prognostic Values of m6A Regulatory Genes in Head and Neck Squamous Cell Carcinoma. Front. Oncol. 10, 718. doi:10.3389/ fonc.2020.00718

Zhu, Y., Wang, X., Forouzmand, E., Jeong, J., Qiao, F., Sowd, G. A., et al. (2018). Molecular Mechanisms for CFIm-Mediated Regulation of mRNA Alternative Polyadenylation. Mol. Cel 69, 62-e4. doi:10.1016/j.molcel.2017.11.031

Zinshteyn, B., and Nishikura, K. (2009). Adenosine-to-inosine RNA Editing. Wires Syst. Biol. Med. 1, 202-209. doi:10.1002/wsbm.10

Zou, D., Dong, L., Li, C., Yin, Z., Rao, S., and Zhou, Q. (2019). The m6A Eraser FTO Facilitates Proliferation and Migration of Human Cervical Cancer Cells. Cancer Cel Int 19, 321. doi:10.1186/s12935-019-1045-1

Conflict of Interest: The authors declare that the research was conducted in the absence of any commercial or financial relationships that could be construed as a potential conflict of interest.

Publisher's Note: All claims expressed in this article are solely those of the authors and do not necessarily represent those of their affiliated organizations, or those of the publisher, the editors and the reviewers. Any product that may be evaluated in this article, or claim that may be made by its manufacturer, is not guaranteed or endorsed by the publisher.

Copyright $\odot 2021$ Huo, Wang, Song, Li, Yu, Wang, Gong, Qiu, Zhu and Zhang. This is an open-access article distributed under the terms of the Creative Commons Attribution License (CC BY). The use, distribution or reproduction in other forums is permitted, provided the original author(s) and the copyright owner(s) are credited and that the original publication in this journal is cited, in accordance with accepted academic practice. No use, distribution or reproduction is permitted which does not comply with these terms. 


\section{GLOSSARY}

3' -UTR 3'-untranslation regions

5'-UTR 5'-untranslated region

ADARs Adenosine deaminase acting on RNA

A-to-I editing Adenosine-to-Inosine Editing

ALKBH5 AlkB homolog 5

ALKBH3 AlkB homolog 3

ASEs Alternative splicing events

APA Alternative Polyadenylation

R Arginine

EGR1 Arly growth response 1

Asn Asparagine

Asp Aspartate

COAD Colorectal Adenocarcinoma

CNV Copy number variations

DDX3 DEAD-box RNA helicase 3

dsRNA Double stranded RNA

DUSP1 Dual specificity phosphatase 1

ESCA Esophageal carcinoma

ESCC Esophageal squamous cell carcinoma

FTO Fat mass and obesity-associated protein

FOXD1-AS1 Forkhead box D1 antisense RNA 1

GRIA2 Glutamate receptor ionotropic AMPA 2

HNSCCs Head and neck squamous cell carcinoma
R/M HNSCC Head and neck squamous cell carcinoma

HCC Hepatocellular carcinoma

HPSCC Hypopharyngeal squamous cell carcinoma

ICIs Immune checkpoint inhibitors

IGFBP7 Insulin-like growth factor-binding protein-7

LSCC Laryngeal squamous cell carcinoma

LIHC Liver Hepatocellular carcinoma

mRNA Messenger RNA

METTL3 Methyltransferase-like 3

METTL14 Methyltransferase-like 14

$\mathbf{m}^{\mathbf{1}} \mathbf{A}$ N1-Methyladenosine

$\mathbf{m}^{\mathbf{6}} \mathbf{A}$ N6-Methyladenosine

NPC Nasopharyngeal carcinoma

ncRNAs Non-coding RNAs

NSCLC Non-small cell lung cancer

OSCC Oral squamous cell carcinoma

PAAD Pancreatic Adenocarcinoma

PTC Papillary thyroid cancer

PD-1/CD279 Programmed cell death protein-1

RBM15 RNA-binding motif protein 15

RBM15B RNA-binding motif protein 15B

STAD Stomach Adenocarcinoma

TNBC Triple-negative breast cancer

ZAR1 Zygote arrest 1 